\title{
Ultradrawing properties of ultra-high molecular weight polyethylene/hydrochloric acid treated attapulgite fibers
}

\author{
Jen-taut Yeh • Chuen-Kai Wang • Chih-Chen Tsai • \\ Chih-Hsueh Lin • Chi-Yuan Huang • Kan-Nan Chen • \\ Kuo-Shien Huang • Shih-Hsuan Chiu
}

Received: 23 January 2013 / Accepted: 8 August 2013 / Published online: 25 August 2013

(C) The Author(s) 2013. This article is published with open access at Springerlink.com

\begin{abstract}
Investigation of the influence of the purified and acid treated attapulgite (ATP) contents on the ultradrawing properties of ultrahigh molecular weight polyethylene/purified attapulgites (UHMWPE/ATP, $\mathrm{F}_{100} \mathrm{~A}_{\mathrm{y}}$ ) and UHMWPE/ acid treated ATP $\left(\mathrm{F}_{100} \mathrm{~A}_{\mathrm{xM}-\mathrm{y}}\right)$ as-prepared fibers is reported. In which, acid treated ATP nanofibers were treated with varying concentrations of hydrochloric solutions for various amounts of time. Similar to those found for the orientation factor values, the achievable draw ratios of the $\mathrm{F}_{100} \mathrm{~A}_{\mathrm{y}}$ and $\mathrm{F}_{100} \mathrm{~A}_{\mathrm{xM}-\mathrm{y}}$ as-prepared fibers and tensile strength values of their drawn fibers approach a maximal value as their purified ATP and/or acid treated ATP
\end{abstract}

\section{J.-t. Yeh $(\bowtie)$}

Hubei Collaborative Innovation Center for Advanced Organic Chemical Materials, Ministry of Education, Key Laboratory for the Green Preparation and Application of Functional Materials, Faculty of Materials Science and Engineering, Hubei University, Wuhan, China

e-mail: jyeh@mail.ntust.edu.tw

J.-t. Yeh • C.-K. Wang • C.-C. Tsai • C.-H. Lin • S.-H. Chiu Graduate School of Material Science and Engineering, National Taiwan University of Science and Technology, Taipei, Taiwan

J.-t. Yeh

Key Laboratory of Green Processing and Functional Textiles of New Textile Materials, Wuhan University of Science and Engineering, Ministry of Education, Wuhan, China

J.-t. Yeh $\cdot$ K.-S. Huang

Department of Materials Engineering, Kun Shan University, Tainan, Taiwan

J.-t. Yeh

School of Printing and Packaging, Wuhan University, Wuhan, China

C.-Y. Huang

Department of Materials Engineering, Tatung University, Taipei, Taiwan

K.-N. Chen

Department of Chemistry, Tamkang University, New Taipei City, Taiwan contents reach the optimal values at 0.05 and $0.025 \mathrm{wt} \%$, respectively. In which, the maximal $D_{r a}$ values of $F_{100} A_{x M}$ 0.025 as-prepared series fiber specimens and the tensile strengths and moduli of the drawn $\mathrm{F}_{100} \mathrm{~A}_{\mathrm{xM}-0.025}$ fiber specimens are significantly higher than those of the $\mathrm{F}_{100} \mathrm{~A}_{0.05}$ drawn fiber specimens prepared at the same draw ratios and optimal ATP contents but without acid treatment. Moreover, it is worth noting that the maximal $\mathrm{D}_{\mathrm{ra}}$ values of the $\mathrm{F}_{100} \mathrm{~A}_{\mathrm{xM}-0.025}$ asprepared fiber specimens and the tensile strengths and moduli of the drawn $\mathrm{F}_{100} \mathrm{~A}_{\mathrm{xM}-0.025}$ fiber specimens reached another maximal value as their ATP nanofibers were treated by $5 \mathrm{M}$ $\mathrm{HCl}$ solutions for $60 \mathrm{~min}$. To understand the interesting ultradrawing, orientation and tensile properties of $\mathrm{F}_{100} \mathrm{~A}_{\mathrm{y}}$ and $\mathrm{F}_{100} \mathrm{~A}_{\mathrm{xM}-\mathrm{y}}$ fiber specimens, Fourier transform infra-red, specific surface areas, scanning electron microcope and elemental analyses of the purified and acid treated ATP nanofibers, and/or morphological and thermal analyses of the $F_{100} A_{y}$ and $\mathrm{F}_{100} \mathrm{~A}_{\mathrm{xM}-\mathrm{y}}$ fiber specimens were performed in this study.

Keywords Ultradrawing - Attapulgite - Acid treatment . Ultrahigh molecular weight polyethylene

\section{Introduction}

Competition among high-performance fibers has prompted new processing methods for obtaining high-performance fibers of ultrahigh molecular weight polyethylene (UHMWPE) [1-11]. The key element in obtaining high-strength UHMWPE fibers is to find a way to draw the as-prepared gel specimens to an ultrahigh draw ratio after the gel spinning process. The drawability of the as-prepared gel specimens was found to depend significantly on the compositions of solutions from which gels were made [12-17]. Several authors [16, 18-22] reported that the drawing temperature and rate could markedly affect the maximal achievable draw ratio and tensile properties of solution-grown UHMWPE samples. In addition to the gel 
solution compositions and drawing conditions, it is generally recognized that the conditions used in the formation process after spinning and/or solution casting of gel solutions can also have a significant influence on the morphology, microstructure and drawing properties of the specimens formed during the above mentioned processes [2, 19, 23-30].

The discovery of carbon nanotubes (CNTs) has attracted enormous attention in recent years due to their remarkable physical characteristics, such as, extremely high Young's modulus and rupture strength, high aspect ratio, nanometerrange diameter [25]. Presumably, incorporation of uniformly dispersed and aligned CNTs in polymer matrix can provide polymer composites with dramatically improved strength and modulus in their machine direction. These expectations have recently been confirmed by a number of studies [26-35]. Our recent investigation [32-34] found that the achievable draw ratios $\left(\mathrm{D}_{\mathrm{ra}}\right)$ of UHMWPE/carbon nanotubes (CNTs) asprepared fibers prepared near the optimal UHMWPE concentration improve consistently and reach a maximal value as their CNT and/or functionalized CNT contents increase up to an optimal value, respectively. As evidenced by DSC thermal analysis, CNTs with extremely high specific surface areas can serve as efficient nucleation sites and facilitate the crystallization of UHMWPE molecules into crystals but with low melting temperatures and/or evaluated smaller crystal thickness during their crystallization processes. Presumably, the crystals with lower melting temperatures and/or evaluated smaller crystal thickness obtained at proper plain and/or functionalized CNT contents can be melted and pulled out of folded lamellar crystals relatively easily during ultradrawing processes, and hence, results in higher drawability and orientation of the UHMWPE/CNTs or UHMWPE/functionalized CNTs asprepared fibers. The ultimate tensile strength values of the UHMWPE/CNTs or UHMWPE/functionalized CNTs drawn fibers prepared using one-stage drawing process at $95^{\circ} \mathrm{C}$ can reach 2.5 and $3.5 \mathrm{GN} \mathrm{m}^{-2}$, respectively, which is about 17 and $66 \%$ higher than that of the corresponding plain UHMWPE drawn fibers prepared at the same optimal UHMWPE concentration and drawing condition but without CNTs.

Similar to CNTs, ATP is a natural clay mineral together with sepiolite that forms the group of fibrous clay minerals with extremely high specific surface areas $\left(\geqq 200 \mathrm{~m}^{2} \mathrm{~g}^{-1}\right)$ [36-40]. Its structure scheme was firstly proposed by Bradly in 1940 [37], who described a theoretical formula of $(\mathrm{Mg}, \mathrm{Al}$, $\mathrm{Fe})_{5} \mathrm{Si}_{8} \mathrm{O}_{20}(\mathrm{Al})(\mathrm{HO})_{2}\left(\mathrm{OH}_{2}\right)_{4} \cdot 4 \mathrm{H}_{2} \mathrm{O}$. In our recent study [41], natural and purified attapulgite (ATP) minerals were added in UHMWPE gel-spinning solutions to improve the ultradrawing and ultimate tensile properties of UHMWPE/ATPs fibers. Similar to those found for UHMWPE/CNTs or UHMWPE/functionalized CNTs as-prepared fibers, the achievable draw ratios of the UHMWPE/ATPs $\left(\mathrm{FA}_{\mathrm{x}}\right)$ and UHMWPE/purified ATPs $\left(\mathrm{FA}_{\mathrm{mx}}\right)$ as-prepared fibers and tensile strength values of their drawn fibers approach a maximal value as their ATPs and/or purified ATPs contents reach the optimal values at 0.02 and $0.015 w t \%$, respectively. The maximal achievable draw ratios of $\mathrm{FA}_{\mathrm{mx}}$ as-prepared series fiber specimens and the tensile strengths of the drawn $\mathrm{FA}_{\mathrm{mx}}$ fiber specimens are significantly higher than those of the corresponding $\mathrm{FA}_{\mathrm{x}}$ drawn fiber specimens prepared at the same draw ratios and ATPs contents but without purification by sodium hexametaphosphate. The ultimate tensile strength values of the UHMWPE/purified ATPs drawn fibers prepared at the optimal ATP content using one-stage drawing process at $95^{\circ} \mathrm{C}$ can reach around $3.9 \mathrm{GN} \mathrm{m}^{-2}$, which is even higher than most of those UHMWPE/functionalized CNTs drawn fibers prepared at the same drawing condition in our previous study $[32-34,41]$. These results clearly suggest that nanofillers with extremely high specific surface areas can act as efficient nucleation sites and significantly improve the achievable draw ratios and ultimate tenacity properties of nanofillers added UHMWPE fibers.

In order to further improve the ultradrawing and ultimate tenacity properties of ATP added UHMWPE fibers, ATP nanofibers were etched by hydrochloric acid with varying concentrations for varying amounts of time to increase their specific surface areas in this study. The maximal achievable draw ratio obtained for each UHMWPE/acid treated ATP asprepared fiber series specimens was significantly higher that of the UHMWPE/purified ATP as-prepared fiber specimens prepared with the same optimal ATP content but without acid treatment. In which, the specific surface areas of ATP nanofibers were found to have a beneficial effect on the ultradrawing and ultimate tenacity properties of UHMWPE/acid treated ATP fibers. In order to understand the significantly improved ultradrawing and ultimate tenacity properties of the UHMWPE/ acid treated ATP fibers, elemental, morphological and Fourier transform infrared analyses of the purified and acid treated ATP specimens and/or thermal, orientation factor, morphological and tensile properties of the as-prepared and drawn UHMWPE/ purified ATP and UHMWPE/acid treated ATP fiber specimens were investigated.

\section{Experimental}

Materials and sample preparation

The UHMWPE resin and attapulgites (ATPs) used in this study were kindly supplied by Yung Chia Chemical Industrial Corporation, Kaohsiung, Taiwan and Xinyuan Science and Technology Corporation, Jiangsu, China, respectively, in which UHMWPE resin is associated with a weight-average molecular weight $(\mathrm{Mw})$ of $5.0 \times 10^{6}$. The ATP ore was first crushed by a hammer and then ground by a planetary ball mill (QMISPO4), which was manufactured by Nanjing University Instrument Plant, Nanjing, China. The ground ATP nanofibers 
were firstly purified in sodium hexametaphosphate (SHMP) deionized water solutions under ultrasonic and stirring condition at $25^{\circ} \mathrm{C}$ for $7 \mathrm{~h}$, in whcih $20 \mathrm{~g}$ of ATP nanofibers together with $0.6 \mathrm{~g}$ of SHMP were dispersed and dissolved in 0.41 of deionized water. Demarcated black impurity was found precipitating from the suspended upper layer solutions after setting the ultrasonic solutions still for half an hour. The suspended upper layer solutions were then centrifuged to remove impurities using a centrifuge model KDC-160HR for $15 \mathrm{~min}$. The centrifuged ATP residue was dried at $80^{\circ} \mathrm{C}$ for $24 \mathrm{~h}$ and then ground into purified ATP nanofibers using the planetary ball mill. Five grams of purified ATP nanofibers were treated with $100 \mathrm{ml}$ of 1, 2, 3, 5 and $7 \mathrm{M}$ hydrochloric acid $(\mathrm{HCl})$ solutions under stirring condition at $70{ }^{\circ} \mathrm{C}$ for varying amounts of time, respectively. In which, $70{ }^{\circ} \mathrm{C}$ was chosen as the acid-treating temperature and used in the above experiments, since the acid treated ATP specimens treated with $3 \mathrm{M} \mathrm{HCl}$ solutions at $70{ }^{\circ} \mathrm{C}$ for $60 \mathrm{~min}$ exhibit significantly higher specific surface areas than those of acid treated ATP fibers treated with other temperatures for $60 \mathrm{~min}$ in our preliminary experiments. After treatment of $\mathrm{HCl}$ solutions, the ATP containing suspensions were filtered and washed with deionized water to neutral. The $\mathrm{HCl}$ treated ATP nanofibers were then dried at $80{ }^{\circ} \mathrm{C}$ for $24 \mathrm{~h}$.

Varying compositions of purified or acid treated ATPs nanofibers together with UHMWPE resin were then dispersed and/or dissolved in decalin solvent at $135{ }^{\circ} \mathrm{C}$ for $1.5 \mathrm{~h}$, in which $0.1 \mathrm{wt} \%$ of di- $t$-butyl- $p$-cresol was added as an antioxidant. The original and/or acid treated ATP nanofibers was dried at $80^{\circ} \mathrm{C}$ for $24 \mathrm{~h}$ in an vacuum oven, before incorporation into the UHMWPE/ATP and/or UHMWPE/acid treated ATP gel solutions. The UHMWPE/ATP and/or UHMWPE/ acid treated ATP gel solutions prepared above were then fed into a temperature-controlled hopper and kept as hot homogenized gel solutions before spinning. The hot homogenized gel solutions were then gel-spun using a conical die with an exit diameter of $1 \mathrm{~mm}$ at an extrusion rate of $1,000 \mathrm{~mm} / \mathrm{min}$ and an extrusion temperature of $170{ }^{\circ} \mathrm{C}$. A water bath and a winder with $70 \mathrm{~mm}$ in diameter were placed at a distance of $520 \mathrm{~mm}$ and $810 \mathrm{~mm}$ from the spinneret exit, respectively. The extruded gel fibers were cooled in a temperatureconditioned atmosphere and then quenched into a water bath for about $1 \mathrm{~min}$, where the temperatures of the air atmosphere and water bath were controlled at $5{ }^{\circ} \mathrm{C}$. The quenched fibers were then extracted in a n-hexane bath for $5 \mathrm{~min}$ to remove the residual decalin solvent. The extracted fiber specimens were then dried in air for $30 \mathrm{~min}$ to remove the remaining $\mathrm{n}$-hexane solvent before any drawing run. Tables 1 and 2 .

Morphological and elemental analysis

In order to understand the morphologies and elemental compositions on the surfaces of the purified and acid treated ATP
Table 1 Designations of purified and acid treated ATP specimens prepared in this study

\begin{tabular}{ll}
$\begin{array}{l}\text { Purified and acid } \\
\text { treated attapulgite } \\
\text { specimens }\end{array}$ & $\begin{array}{l}\text { Concerntrations of } \\
\text { hydrochrolic acid } \\
\text { solutions (M) }\end{array}$ \\
\hline $\mathrm{A}$ & 0 \\
$\mathrm{~A}_{1 \mathrm{M}}$ & 1 \\
$\mathrm{~A}_{2 \mathrm{M}}$ & 2 \\
$\mathrm{~A}_{3 \mathrm{M}}$ & 3 \\
$\mathrm{~A}_{5 \mathrm{M}}$ & 5 \\
$\mathrm{~A}_{7 \mathrm{M}}$ & 7 \\
\hline
\end{tabular}

Table 2 Designations and compositions of UHMWPE, UHMWPE/ATP and UHMWPE/acid treated ATP as-prepared fiber specimens

\begin{tabular}{|c|c|c|c|c|}
\hline $\begin{array}{l}\text { As-prepared } \\
\text { fiber } \\
\text { specimens }\end{array}$ & $\begin{array}{l}\text { ATP } \\
\text { (phr) }\end{array}$ & $\begin{array}{l}\text { Acid treated } \\
\text { ATP } \\
\text { (phr) }\end{array}$ & $\begin{array}{l}\text { UHMWPE } \\
\text { (g) }\end{array}$ & $\begin{array}{l}\text { Volumes of } \\
\text { decalin in gel } \\
\text { solutions (ml) }\end{array}$ \\
\hline $\mathrm{F}_{100}$ & 0 & 0 & 100 & 5000 \\
\hline $\mathrm{F}_{100} \mathrm{~A}_{0.0125}$ & 0.0125 & - & 100 & 5000 \\
\hline $\mathrm{F}_{100} \mathrm{~A}_{0.025}$ & 0.025 & - & 100 & 5000 \\
\hline $\mathrm{F}_{100} \mathrm{~A}_{0.05}$ & 0.05 & - & 100 & 5000 \\
\hline $\mathrm{F}_{100} \mathrm{~A}_{0.15}$ & 0.15 & - & 100 & 5000 \\
\hline $\mathrm{F}_{100} \mathrm{~A}_{0.25}$ & 0.25 & - & 100 & 5000 \\
\hline $\mathrm{F}_{100} \mathrm{~A}_{1 \mathrm{M}-0.0125}$ & - & 0.0125 & 100 & 5000 \\
\hline $\mathrm{F}_{100} \mathrm{~A}_{1 \mathrm{M}-0.025}$ & - & 0.025 & 100 & 5000 \\
\hline $\mathrm{F}_{100} \mathrm{~A}_{1 \mathrm{M}-0.05}$ & - & 0.05 & 100 & 5000 \\
\hline $\mathrm{F}_{100} \mathrm{~A}_{1 \mathrm{M}-0.15}$ & - & 0.15 & 100 & 5000 \\
\hline $\mathrm{F}_{100} \mathrm{~A}_{1 \mathrm{M}-0.25}$ & - & 0.25 & 100 & 5000 \\
\hline $\mathrm{F}_{100} \mathrm{~A}_{2 \mathrm{M}-0.0125}$ & - & 0.0125 & 100 & 5000 \\
\hline $\mathrm{F}_{100} \mathrm{~A}_{2 \mathrm{M}-0.025}$ & - & 0.025 & 100 & 5000 \\
\hline $\mathrm{F}_{100} \mathrm{~A}_{2 \mathrm{M}-0.05}$ & - & 0.05 & 100 & 5000 \\
\hline $\mathrm{F}_{100} \mathrm{~A}_{2 \mathrm{M}-0.15}$ & - & 0.15 & 100 & 5000 \\
\hline $\mathrm{F}_{100} \mathrm{~A}_{2 \mathrm{M}-0.25}$ & - & 0.25 & 100 & 5000 \\
\hline $\mathrm{F}_{100} \mathrm{~A}_{3 \mathrm{M}-0.0125}$ & - & 0.0125 & 100 & 5000 \\
\hline $\mathrm{F}_{100} \mathrm{~A}_{3 \mathrm{M}-0.025}$ & - & 0.025 & 100 & 5000 \\
\hline $\mathrm{F}_{100} \mathrm{~A}_{3 \mathrm{M}-0.05}$ & - & 0.05 & 100 & 5000 \\
\hline $\mathrm{F}_{100} \mathrm{~A}_{3 \mathrm{M}-0.15}$ & - & 0.15 & 100 & 5000 \\
\hline $\mathrm{F}_{100} \mathrm{~A}_{3 \mathrm{M}-0.25}$ & - & 0.25 & 100 & 5000 \\
\hline $\mathrm{F}_{100} \mathrm{~A}_{5 \mathrm{M}-0.0125}$ & - & 0.0125 & 100 & 5000 \\
\hline $\mathrm{F}_{100} \mathrm{~A}_{5 \mathrm{M}-0.025}$ & - & 0.025 & 100 & 5000 \\
\hline $\mathrm{F}_{100} \mathrm{~A}_{5 \mathrm{M}-0.05}$ & - & 0.05 & 100 & 5000 \\
\hline $\mathrm{F}_{100} \mathrm{~A}_{5 \mathrm{M}-0.15}$ & - & 0.15 & 100 & 5000 \\
\hline $\mathrm{F}_{100} \mathrm{~A}_{5 \mathrm{M}-0.25}$ & - & 0.25 & 100 & 5000 \\
\hline $\mathrm{F}_{100} \mathrm{~A}_{7 \mathrm{M}-0.0125}$ & - & 0.0125 & 100 & 5000 \\
\hline $\mathrm{F}_{100} \mathrm{~A}_{7 \mathrm{M}-0.025}$ & - & 0.025 & 100 & 5000 \\
\hline $\mathrm{F}_{100} \mathrm{~A}_{7 \mathrm{M}-0.05}$ & - & 0.05 & 100 & 5000 \\
\hline $\mathrm{F}_{100} \mathrm{~A}_{7 \mathrm{M}-0.15}$ & - & 0.15 & 100 & 5000 \\
\hline $\mathrm{F}_{100} \mathrm{~A}_{7 \mathrm{M}-0.25}$ & - & 0.25 & 100 & 5000 \\
\hline
\end{tabular}


nanofiber specimens prepared in "Materials and sample preparation" section. The original, purified and acid treated ATP nanofibers were dried at $80^{\circ} \mathrm{C}$ for $24 \mathrm{~h}$ and then gold-coated at $15 \mathrm{kev}$ for $10 \mathrm{~s}$. The original, purified and acid treated ATP nanofibers were also dried and dispersed in alcohol and then dried onto a carbon-coated copper grid under ambient conditions prior to morphological and elemental analysis. A special accessory kit (attenuated total reflectance (ATR)) was used in elemental analysis to determine the content of light elements such as oxygen in original and/or acid treated ATP nanofibers. The UHMWPE, UHMWPE/purified ATP and UHMWPE/ acid treated ATP as-prepared and drawn gel fibers were etched with excess amount of fuming nitric acid to highlight the crystalline morphology of the fiber specimen. The amorphous regions of fiber specimens could be etched with ultrasonic generator at $300 \mathrm{~W}$ at $60^{\circ} \mathrm{C}$. After the $6 \mathrm{~h}$ acid treatment the sample was washed subsequently by both de-ionized water by boiling acetone, and then dried at room temperature. The dried etched fiber specimens were then gold-coated at $15 \mathrm{kev}$ for $10 \mathrm{~s}$. The gold-coated ATP nanofiber and fiber specimens prepared above were then examined using a JEOL Field Emission Scanning Electron Microscope (FESEM) model JSM-6500 operated at $15 \mathrm{kV}$.

\section{Specific surface area analysis}

A Laser Particle Size Analyzer model BT-9300H (Dandong Bettersize Instruments Ltd., Dandong, China) was used to study the specific surface areas of the purified and acid treated ATP specimens prepared in the "Materials and sample preparation" section, although the specific surface areas of ATP and/or acid treated ATP fibers may be underestimated due to their porosity and surface roughness in feature. Before analysis, ten micrograms of purified and acid treated ATP nanofibers were added and ultrasonicated in $10 \mathrm{ml}$ decalin at $25^{\circ} \mathrm{C}$ for $5 \mathrm{~min}$, respectively. The specific surface areas of purified and acid treated ATP specimens were then measured by placing the ultrasonicated solutions prepared above in the curette of the Laser Particle Size Analyzer at $25^{\circ} \mathrm{C}$.

Fourier transform infrared spectroscopy

Fourier transform infrared (FT-IR) spectroscopic measurements of the purified and acid treated ATP specimens were recorded on a Nicolet Avatar 360 FT-IR spectrophotometer at $25{ }^{\circ} \mathrm{C}$, wherein 32 scans with a spectral resolution $1 \mathrm{~cm}^{-1}$ were collected during each spectroscopic measurement. Infrared spectra of the film specimens were determined using the conventional $\mathrm{KBr}$ disk method. The original and modified ATP nanofibers were cast onto $\mathrm{KBr}$ disk and dried at $60{ }^{\circ} \mathrm{C}$ for $30 \mathrm{~min}$. The cast films used in this study were prepared sufficiently thin enough to obey the Beer-Lambert law.
Thermal, lamellar thickness and orientation factor analysis

Thermal properties of all samples were performed on a TA differential scanning calorimeter (DSC) model Q100. All scans were carried out at a heating rate of $20^{\circ} \mathrm{C} / \mathrm{min}$ under flowing nitrogen at a flow rate of $25 \mathrm{ml} / \mathrm{min}$. Samples weighing $0.5 \mathrm{mg}$ and $15 \mathrm{mg}$ were placed in the standard aluminum sample pans for determination of their melting temperature $\left(\mathrm{T}_{\mathrm{m}}\right)$ and percentage crystallinity values, respectively. The percentage crystallinity values of the specimens were estimated using baselines drawn from 40 to $200{ }^{\circ} \mathrm{C}$ and a perfect heat of fusion of polyethylene of $293 \mathrm{~J} / \mathrm{g}[42,43]$.

In order to understand the ultradrawing properties of UHMWPE, UHMWPE/ATP and UHMWPE/acid treated ATP as-prepared fiber specimens, the lamellar thickness $\left(l_{c}\right)$ values of the above as-prepared fibers were evaluated from their $T_{m}$ values using Hoffman and Week's equation [43, 44] given as follows. Broad melting peak observed from nonisothermal DSC scans and the effect of lamella thickening may all lead to deviations from the true $l_{c}$ values. Nevertheless, Hoffman-Weeks equation was used for qualitative estimation of $l_{c}$ values of UHMWPE, UHMWPE/ATP and/or UHMWPE/acid treated ATP as-prepared fiber specimens, because it is the most feasible technique one can use to estimate the $1_{c}$ values of fiber specimens. In which, an equilibrium melting temperature $\left(\mathrm{T}_{\mathrm{m}}^{\mathrm{o}}\right)$ of $145.5^{\circ} \mathrm{C}$, a perfect heat of fusion $\left(\Delta \mathrm{H}_{\mathrm{f}}^{0}\right)$ of $293 \mathrm{~J} / \mathrm{g}$ and a folded surface free energy $\left(\sigma_{\mathrm{e}}\right)$ of $9 \times 10^{-6} \mathrm{~J} / \mathrm{cm}^{2}$ of polyethylene crystals [43] were used for evaluation of $l_{c}$ values of UHMWPE, UHMWPE/ATP and UHMWPE/acid treated ATP as-prepared fiber specimens.

$\mathrm{T}_{\mathrm{m}}=\mathrm{T}_{\mathrm{m}}^{\mathrm{o}}\left[1-\frac{2 \sigma_{\mathrm{e}}}{1 \mathrm{c} \Delta \mathrm{H}_{\mathrm{f}}^{0}}\right]$

The orientation factor $\left(\mathrm{f}_{\mathrm{o}}\right)$ values of UHMWPE, UHMWPE/ ATP and UHMWPE/acid treated ATP as-prepared and drawn fiber specimens were measured using a sonic velocity orientation instrument model SCY-III, which was purchased from Donghuakaili Chemicals and Fiber Technology Corporation, Shanghai, China. Before testing, the fiber specimen with $60 \mathrm{~cm}$ in length was wound and clamped on a testing device with a span of $40 \mathrm{~cm}$. The $\mathrm{f}_{\mathrm{o}}$ values of the as-spun and drawn fiber specimens were then measured at $25^{\circ} \mathrm{C}$. A minimum of five samples of each specimen were tested and averaged during the orientation measurements. The $\mathrm{f}_{0}$ values were evaluated using Eq. (2) as suggested by Xiao and coauthors [45]:

$\mathrm{f}_{0}=1-\left(\mathrm{C}_{\mathrm{u}} / \mathrm{C}\right)^{2}$

where $\mathrm{C}$ is the sonic velocity of the as-prepared or drawn UHMWPE fiber specimen and $\mathrm{Cu}$ is the sonic velocity of the fully unoriented sample, taken as $1.65 \mathrm{~km} / \mathrm{s}$ [45]. 
Drawing and tensile properties of the fiber specimens

The UHMWPE, UHMWPE/ATP and UHMWPE/acid treated ATP fiber specimens used in the drawing experiments were cut from the dried as-prepared fibers and then stretched on a Gotech tension testing machine model GT-TFS-2000 equipped with a temperature-controlled oven. The fibers are $20 \mathrm{~mm}$ in length, which were wound and clamped in a stretching device and then stretched at $95{ }^{\circ} \mathrm{C}$ and a crosshead speed of $20 \mathrm{~mm} / \mathrm{min}$. The draw ratio of each fiber specimen was determined as the ratio of the marked displacement after and before drawing. The marked displacement before drawing was $27 \mathrm{~mm}$. The tensile properties of the as-prepared and drawn fiber specimens were also determined using a HungTa tension testing machine model HT-9112 at a crosshead speed of $20 \mathrm{~mm} / \mathrm{min}$. A minimum of five samples of each specimen were tested and averaged during the tensile experiments.

\section{Results and Discussion}

Morphological analyses of the original, purified and acid treated ATPs

Figure 1 exhibits typical SEM micrographs of original, purified and acid treated ATP specimens. Typical rodlike feature with dimensions of 150-600 $\mathrm{nm}$ in length and $10-45 \mathrm{~nm}$ in diameter was observed for original and purified ATP specimens. Before purification, the rodlike ATP nanofibers were found agglomerating and/or bundling together significantly on SEM micrograph of the original ATP specimen (see Fig. 1a). As shown in Fig 1b, the agglomerated bundles of ATP nanofibers originally present in original ATP specimen were significantly dispersed after the impurities were removed between ATP nanofibers. After acid treatment for a fixed amount of time, the surface roughness of acid treated ATP nanofibers seemed to increase due to hydrochloric acid etching even at low $\mathrm{HCl}$ concentrations, although agglomeration of ATP nanofibers was still present in acid-treated ATP specimens without ultrasonication. Moreover, the rodlike feature of ATP nanofibers were significantly etched into broken/shorter and thinner nanofibers by $\mathrm{HCl}$ solutions as their concentrations increase from 1 to $7 \mathrm{M}$ (see Figs. 1c to g). In fact, after etching by $7 \mathrm{M} \mathrm{HCl}$ solution for $60 \mathrm{~min}$, nearly only broken/short ATP nanofibers were found on the SEM micrograph of $\mathrm{A}_{7 \mathrm{M}}$ specimen (see Fig. 1g).

Figure 2 summarized typical SEM micrographs of $A_{5 M}$ specimens treated with $5 \mathrm{M} \mathrm{HCl}$ solution for various amounts of time. Similarly, after treating with $5 \mathrm{M} \mathrm{HCl}$ solutions, the rodlike feature of ATP nanofibers were etched into broken/ shorter and thinner rodlike feature as the treating time increase from 20 to $100 \mathrm{~min}$ (see Fig. 2a to e). In fact, nearly only broken and short ATP nanofibers were found on the SEM micrograph of $A_{5 M}$ specimens after they were excessive etched with $5 \mathrm{M} \mathrm{HCl}$ solutions for more than $60 \mathrm{~min}$ (see Fig. 2d to e).

Elemental analyses of the original, purified and acid treated ATPs

Table 3 summarized the compositions of original, purified and acid treated ATP specimens after elemental analyses. Elements, such as $\mathrm{Si}, \mathrm{Al}$ and $\mathrm{Mg}$ were found [46] as the main compositions on the surfaces of original ATPs. The small amounts of $\mathrm{P}, \mathrm{Ca}, \mathrm{Ni}$ and $\mathrm{Ti}$ elements found on the surfaces of original ATPs are ascribed as the impurities that present as mineral compounds in the original ATPs, in which Ca element is reported present as $\mathrm{CaCO}_{3}$ containing minerals [47]. After purification, the contents of $\mathrm{Ca}, \mathrm{Ni}$ and $\mathrm{Ti}$ elements reduce significantly to $0.4,0.6$ and $0.3 \mathrm{wt} \%$, respectively; but $\mathrm{P}$ contents increase from 0.5 to $4.3 \mathrm{wt} \%$. Moreover, as shown in Table 4, Ca, Ni and Ti elements were indeed found as the main compositions of sediments after purification processes. These results suggest that $\mathrm{Ca}, \mathrm{Ni}$ and $\mathrm{Ti}$ contained impurities originally present on the surfaces of ATP nanofibers precipitated as black sediments after their purification processes. During purification processes of ATP nanofibers, the abundant unbalanced charges present on surfaces of ATPs are likely to adsorb SHMP molecules with high P contents. As a consequence, $\mathrm{Ni}$, Ti and $\mathrm{Ca}$ contained impurities reduce but $\mathrm{P}$ contained impurities increase significantly after the purification processes of ATP nanofibers.

After acid treatment for $60 \mathrm{~min}$, the contents of $\mathrm{P}, \mathrm{Ni}$ and Ti elements found on the surfaces of acid treated ATP nanofibers restore gradually to those contents found for the original ATP nanofibers, respectively, as the hydrochloric acid $(\mathrm{HCl})$ concentrations used acid treatment increase from 1 to $7 \mathrm{M}$. In contrast, the contents of $\mathrm{Ca}$ element found on the surfaces of acid treated ATP specimens treated with $\mathrm{HCl}$ solutions for $60 \mathrm{~min}$ remain at low values 0.2 to $0.4 \mathrm{wt} \%$, which are about the same as those found for the purified ATP specimens. As evidenced by morphological analyses in the previous section, after $60 \mathrm{~min}$ of acid treatment, the rodlike feature of ATP nanofibers were significantly etched into broken/shorter and/ or thinner rodlike feature by $\mathrm{HCl}$ solutions as their concentrations increase from 1 to $7 \mathrm{M}$. These results clearly suggest that $\mathrm{P}, \mathrm{Ni}$ and Ti elements originally present in ATP nanofibers gradually exposed after acid treatment for $60 \mathrm{~min}$ and $\mathrm{P}, \mathrm{Ni}$ and $\mathrm{Ti}$ contents restored gradually to those found for purified ATP nanofibers, as the $\mathrm{HCl}$ concentrations used in the acid treatment increased from 1 to $7 \mathrm{M}$. The relatively low $\mathrm{Ca}$ contents found on the surfaces of acid treated ATP specimens is attributed to the easy dissolution of newly exposed $\mathrm{CaCO}_{3}$ impurities in $\mathrm{HCl}$ solutions during the acid treating processes. 

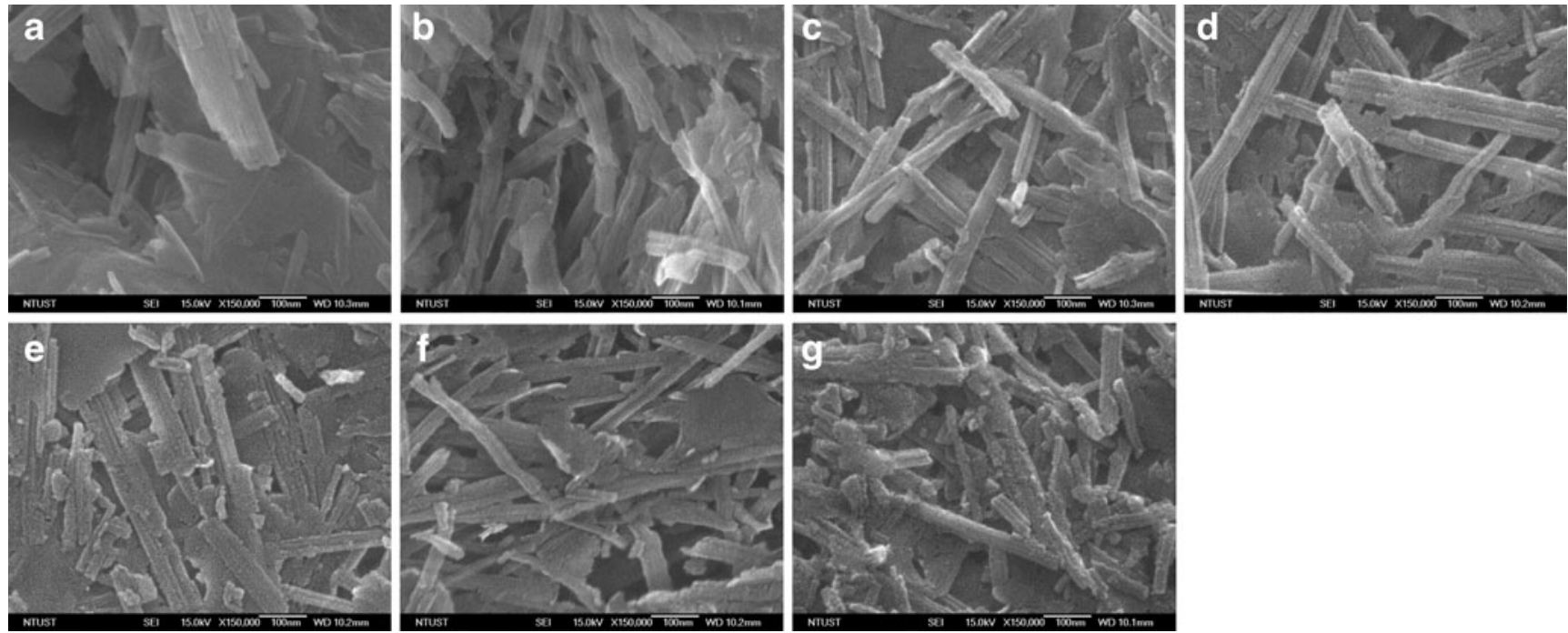

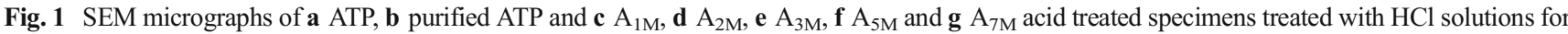
$60 \mathrm{~min}$

Specific surface area analyses

The values of specific surface areas of the purified and acid treated ATP nanofibers are summarized in Fig. 3. The specific surface area of the purified ATPs is relatively high and reaches $205 \mathrm{~m}^{2} / \mathrm{g}$. After the treatment of $\mathrm{HCl}$ solutions, the specific surface areas of acid treated ATP nanofibers are significantly higher than those of the purified ATP nanofibers. In fact, the specific surface areas of each acid treated ATP nanofibers increase significantly with the increase in treating time, and then reach a maximal value as the treating time approaches an appropriate value around $60 \mathrm{~min}$. The maximal specific surface areas obtained for acid treated ATP specimens reach another maximal value as the concentrations of $\mathrm{HCl}$ solutions used for $60 \mathrm{~min}$ of acid treatment approach an optimal value at $5 \mathrm{M}$. As shown in Fig. 3, after treating ATP nanofibers in $5 \mathrm{M}$ $\mathrm{HCl}$ solution for $60 \mathrm{~min}$, the specific surface areas of the acid treated ATP nanofibers reaches around $282 \mathrm{~m}^{2} / \mathrm{g}$, which is about $40 \%$ higher than the specific surface area of purified ATP nanofibers without acid treatment. At $\mathrm{HCl}$ concentrations higher than $5 \mathrm{M}$ or treating time more than the optimal value at $60 \mathrm{~min}$, the specific surface areas of the acid treated ATP nanofibers reduce significantly with the further increase in the $\mathrm{HCl}$ concentration or treating time. For instance, the maximal specific surface areas of the ATP nanofibers acidtreated for an optimal amount of time at $60 \mathrm{~min}$ reduce from $282 \mathrm{~m}^{2} / \mathrm{g}$ to $250 \mathrm{~m}^{2} / \mathrm{g}$, as the $\mathrm{HCl}$ concentrations increase from $5 \mathrm{M}$ to $7 \mathrm{M}$. Similarly, the specific surface areas of ATP
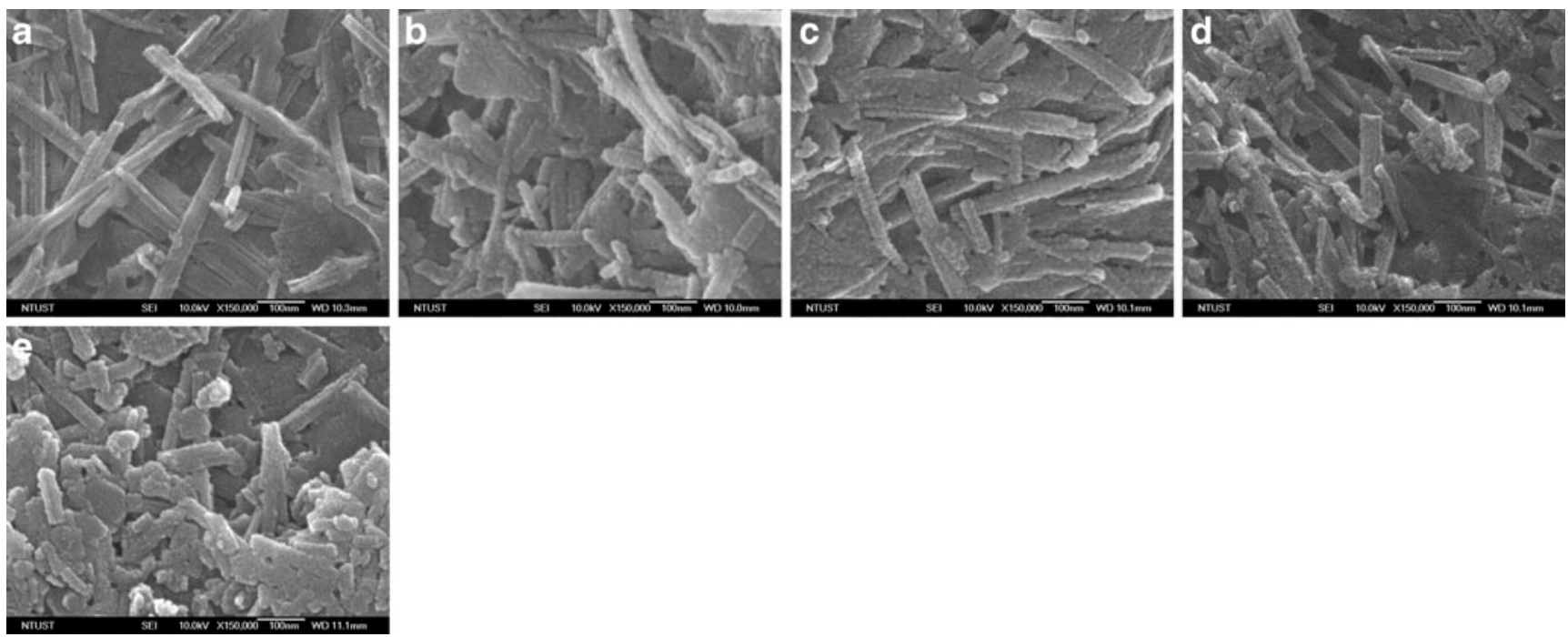

Fig. 2 SEM micrographs of acid treated ATP specimens after acid treatment with $5 \mathrm{M} \mathrm{HCl}$ solution for a 20, b 40, c 60, d 80, and e 100 min 
Table 3 Elemental analyses of original, purified and acid treated ATP specimens

\begin{tabular}{llllllll}
\hline $\begin{array}{l}\text { Compositions } \\
(\text { wt } \%)\end{array}$ & ATP & Purified ATP & $\mathrm{A}_{1 \mathrm{M}}$ & $\mathrm{A}_{2 \mathrm{M}}$ & $\mathrm{A}_{3 \mathrm{M}}$ & $\mathrm{A}_{5 \mathrm{M}}$ & $\mathrm{A}_{7 \mathrm{M}}$ \\
\hline $\mathrm{Si}$ & 62.5 & 62.4 & 62.4 & 62.3 & 62.4 & 62.5 & 62.3 \\
$\mathrm{Al}$ & 15.4 & 15.2 & 15.3 & 15.3 & 15.4 & 15.3 & 15.5 \\
$\mathrm{Mg}$ & 9.5 & 9.4 & 9.3 & 9.5 & 9.6 & 9.4 & 9.5 \\
$\mathrm{P}$ & 0.5 & 4.3 & 3.8 & 3.1 & 2.6 & 1.9 & 1.0 \\
$\mathrm{Ni}$ & 1.9 & 0.6 & 0.7 & 0.9 & 1.2 & 1.4 & 1.5 \\
$\mathrm{Ti}$ & 1.6 & 0.3 & 0.6 & 0.7 & 0.9 & 1.2 & 1.4 \\
$\mathrm{Ca}$ & 4.1 & 0.4 & 0.4 & 0.3 & 0.2 & 0.2 & 0.2 \\
\hline
\end{tabular}

nanofibers treated with $5 \mathrm{M} \mathrm{HCl}$ concentration reduce from $282 \mathrm{~m}^{2} / \mathrm{g}$ to $275 \mathrm{~m}^{2} / \mathrm{g}$, as the treating time increases from 60 to $80 \mathrm{~min}$. As evidenced by morphological analysis in the previous section, the significant reduction in specific surface areas of acid treated ATP nanofibers with excessive treating time or $\mathrm{HCl}$ concentrations is attributed to the collapse of long ATP nanofibers originally with many free tunnels into significantly thinner and shorter ATP nanafibers with less free tunnels or cavities caused by over-etching of the $\mathrm{HCl}$ solutions.

\section{Fourier transform infra-red spectroscopy}

Figure 4 illustrates typical Fourier transform infra-red (FT-IR) spectra of original, purified and acid treated ATP specimens. As shown in the FT-IR spectrum of the original ATP specimen, seven distinguished absorption bands were found centering at 793, 882, 1,194, 1,433, 1,655, 3,582 and 3,616 $\mathrm{cm}^{-1}$, which were generally ascribed to the motions of Ti-O bending, carbonate bending, $\mathrm{Mg}-\mathrm{O}$ stretching, carbonate bending, absorbed water bending, $\mathrm{Al}-\mathrm{Mg}-\mathrm{OH}$ bending and $\mathrm{Al}_{2}-\mathrm{OH}$ bending, respectively[41, 46]. After purification, the Ti-O and carbonate bending bands nearly disappeared, while demarcated $\mathrm{Mg}-\mathrm{O}$ stretching, absorbed water bending, Al-Mg$\mathrm{OH}$ bending and $\mathrm{Al}_{2}-\mathrm{OH}$ bending bands were found centering at $1,195,1,657,3,583$ and $3,616 \mathrm{~cm}^{-1}$ of the FT-IR spectrum of purified ATP specimen (see Fig. 4b), respectively. Similar to those found for purified ATP specimen, demarcated Mg-O

\begin{tabular}{lll}
\cline { 2 - 2 } $\begin{array}{l}\text { Table 4 Elemental } \\
\text { analyses of sediments } \\
\text { after the purification } \\
\text { processes of ATP }\end{array}$ & Compositions (wt\%) & Sediments \\
\cline { 2 - 3 } specimens & $\mathrm{Si}$ & 0.05 \\
& $\mathrm{Al}$ & 0.06 \\
& $\mathrm{Mg}$ & 0.09 \\
& $\mathrm{P}$ & 0.5 \\
& $\mathrm{Ni}$ & 37.5 \\
& $\mathrm{Ti}$ & 32.4 \\
& $\mathrm{Ca}$ & 16.3 \\
\hline
\end{tabular}

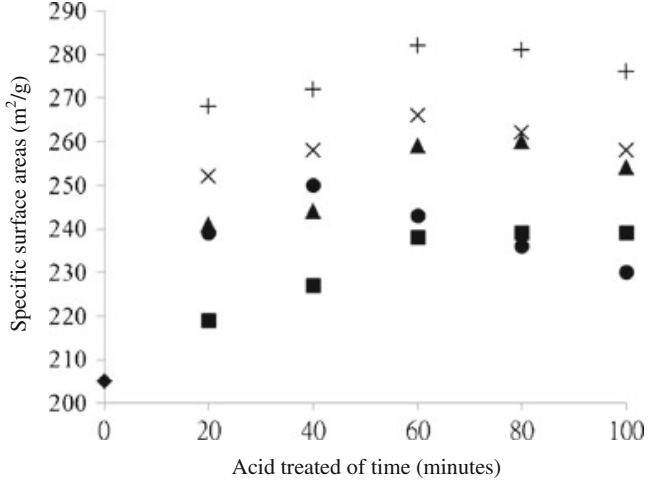

Fig. 3 Specific surface areas of $A(\bullet), A_{1 M}(\bullet), A_{2 M}(\boldsymbol{\Delta}), A_{3 M}(\times), A_{5 M}$ $(+)$ and $\mathrm{A}_{7 \mathrm{M}}(\bullet)$ specimens

stretching, absorbed water bending, $\mathrm{Al}-\mathrm{Mg}-\mathrm{OH}$ bending and $\mathrm{Al}_{2}-\mathrm{OH}$ bending bands were found centering at $1,195,1,657$, 3,583 and $3,615 \mathrm{~cm}^{-1}$, respectively, of the FT-IR spectra of acid treated ATP specimen. However, Ti-O bending bands reappeared gradually and became more demarcated as $\mathrm{HCl}$ concentrations used for acid treatment increased from 1 to $7 \mathrm{M}$.

The disappearance of the Ti-O bending bands of purified ATP specimem is likely due to the adsorption of $\mathrm{Ti}^{2+}$ by SHMP after purification of ATP nanofibers. Whereas, the reappearance of Ti-O bending bands of acid treated ATP specimens is attributed to the newly exposed impurities containing Ti-O groups after acid treatment of purified ATP nanofibers. The disappearance of carbonate bending bands of the purified ATP specimens is most likely due to the adsorption of $\mathrm{Ca}^{2+}$ by SHMP after purification of ATP nanofibers, wherein $\mathrm{CO}_{3}{ }^{2-}$ anions were combined with $\mathrm{Na}^{+}$cations of SHMP to form $\mathrm{Na}_{2} \mathrm{CO}_{3}$ and then dissolved or precipitated in water. In contrast, the disappearance of carbonate bending bands of the acid treated ATP specimens is attributed to the easy dissolution of newly exposed $\mathrm{CaCO}_{3}$ impurities in $\mathrm{HCl}$ solutions during the acid treating processes.

Thermal properties of the as-prepared fibers

Typical DSC thermograms of UHMWPE $\left(\mathrm{F}_{100}\right)$, UHMWPE/ purified ATP $\left(\mathrm{F}_{100} \mathrm{~A}_{\mathrm{y}}\right)$ and UHMWPE/acid treated ATP $\left(\mathrm{F}_{100} \mathrm{~A}_{\mathrm{xM}-\mathrm{y}}\right)$ as-prepared fiber series specimens are summarized in Figs. 5, 6, 7, 8, 9 and 10. Table 5 summarized the lamellar thickness $\left(\mathrm{l}_{\mathrm{c}}\right)$ values of $\mathrm{F}_{100}, \mathrm{~F}_{100} \mathrm{~A}_{\mathrm{y}}$ and $\mathrm{F}_{100} \mathrm{~A}_{\mathrm{xM}-\mathrm{y}}$ as-prepared fiber specimens evaluated from their melting temperature $\left(\mathrm{T}_{\mathrm{m}}\right)$ values using Hoffman and Week's equation [43, 44]. A main melting endotherm with a peak melting temperature $\left(\mathrm{T}_{\mathrm{m}}\right)$ and percentage crystallinity $\left(\mathrm{X}_{\mathrm{c}}\right)$ at $139.6{ }^{\circ} \mathrm{C}$ and $65.3 \%$, respectively, was found for the $\mathrm{F}_{100}$ as-prepared fiber specimen. The $T_{m}$ (or evaluated $l_{c}$ ) and $X_{c}$ values of $F_{100} A_{y}$ and/or $\mathrm{F}_{100} \mathrm{~A}_{\mathrm{xM} \text {-y }}$ as-prepared fiber series specimens approach the minimal and maximal values, as their purified and/or acid treated ATP approach the optimal values at 0.05 and 0.025 phr, respectively. In which, $T_{m}$ (or evaluated $l_{c}$ ) and $X_{c}$ values 
Fig. 4 FT-IR spectra of the a

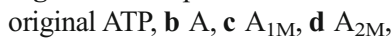
e $A_{3 M}, f A_{5 M}$ and $\mathbf{g ~} A_{7 M}$ specimens

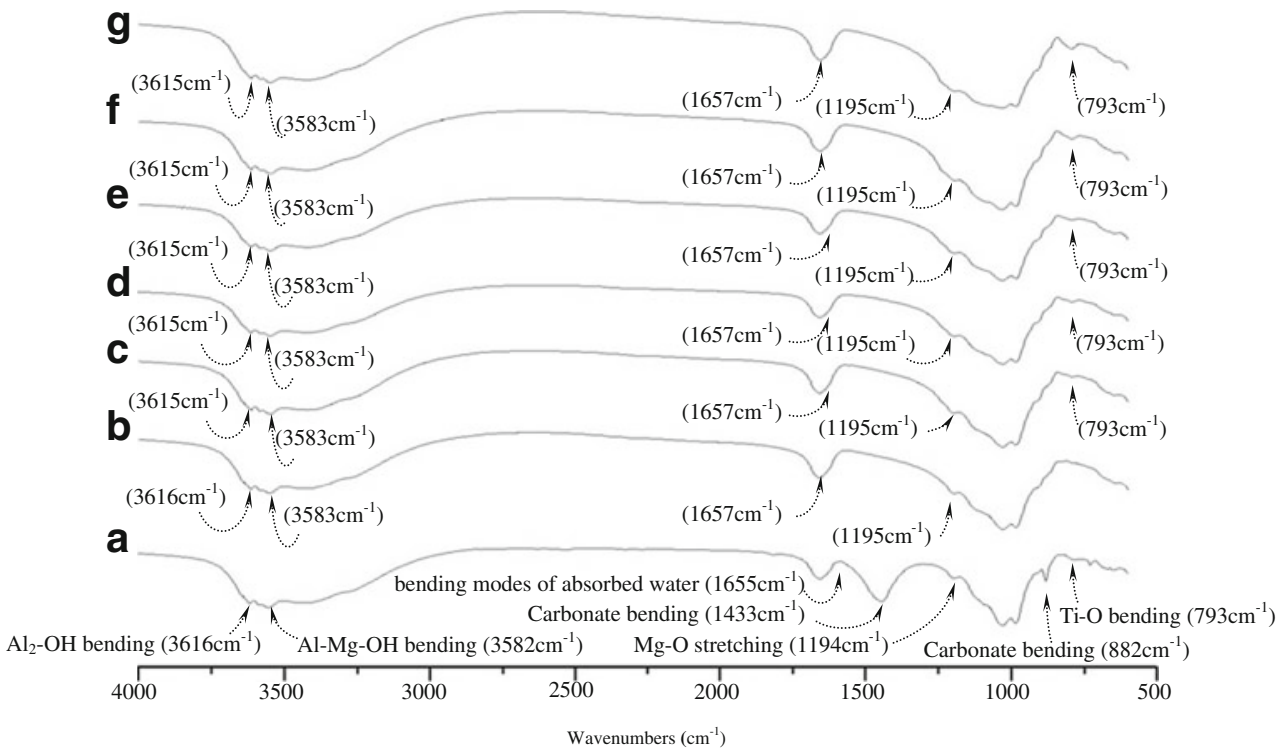

of the $\mathrm{F}_{100} \mathrm{~A}_{\mathrm{xM} \text {-y }}$ as-prepared fiber specimens are significantly lower and higher than those of the corresponding $\mathrm{F}_{100} \mathrm{~A}_{\mathrm{y}}$ asprepared fiber specimens, respectively. For instance, $\mathrm{T}_{\mathrm{m}}, \mathrm{l}_{\mathrm{c}}$ and $\mathrm{X}_{\mathrm{c}}$ values of $\mathrm{F}_{100} \mathrm{~A}_{5 \mathrm{M}-0.025} / \mathrm{F}_{100} \mathrm{~A}_{1 \mathrm{M}-0.05}$ as-prepared fiber specimen are $135.8{ }^{\circ} \mathrm{C} / 137.4{ }^{\circ} \mathrm{C}, 9.6 \mathrm{~nm} / 11.5 \mathrm{~nm}$ and $74.6 \% /$ $70.2 \%$, respectively, which are significantly lower than $\mathrm{T}_{\mathrm{m}}$ and $l_{c}$ values (i.e. $139.6{ }^{\circ} \mathrm{C}, 15.7 \mathrm{~nm}$ ), but higher than $\mathrm{X}_{\mathrm{c}}$ values (i.e. $65.3 \%$ ) of $\mathrm{F}_{100}$ as-prepared fiber specimen. Moreover, it is worth noting that each $\mathrm{F}_{100} \mathrm{~A}_{5 \mathrm{M}-\mathrm{y}}$ as-prepared fiber series specimen exhibits the lowest $T_{m}$ (or evaluated $l_{c}$ ) but the highest $\mathrm{X}_{\mathrm{c}}$ values among $\mathrm{F}_{100} \mathrm{~A}_{\mathrm{xM} \text {-y }}$ as-prepared fiber series specimens with the same contents of acid treated ATP nanofibers treating with different $\mathrm{HCl}$ concentrations for $60 \mathrm{~min}$ (see Figs. 5, 6, 7, 8, 9 and 10). For instance, the $\mathrm{T}_{\mathrm{m}}$ (or evaluated $\mathrm{l}_{\mathrm{c}}$ ) and $\mathrm{X}_{\mathrm{c}}$ values of $\mathrm{F}_{100} \mathrm{~A}_{5 \mathrm{M}-0.025}$ as-prepared fiber are about 0.3 to $0.8{ }^{\circ} \mathrm{C}$ (or 0.3 to $0.9 \mathrm{~nm}$ ) lower and 0.9 to $3.2 \%$ higher than those of other corresponding $\mathrm{F}_{100} \mathrm{~A}_{\mathrm{xM}-0.025}$

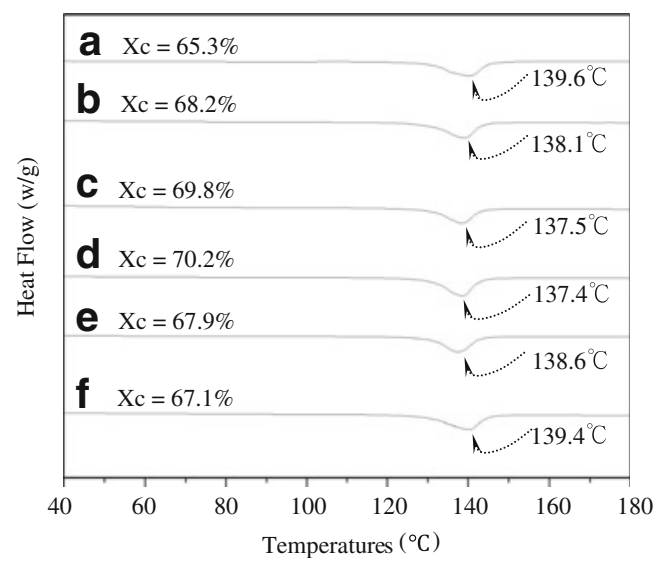

Fig. 5 DSC thermograms of a F100, b F100A0.0125, c F100A0.025, d F100A0.05, e F100A0.15, f F100A0.25 as-prepared fiber specimens as-prepared fiber specimens with the same contents of acid treated ATP nanofibers treating with $\mathrm{HCl}$ concentrations other than $5 \mathrm{M}$ for $60 \mathrm{~min}$.

As evidenced by the specific surface area and SEM analyses, the purified and acid treated ATP nanofibers are with relatively large surface areas per volume, which make them in close proximity to a large fraction of the UHMWPE matrix. Apparently, even small contents of purified and acid treated ATP nanofibers can serve as efficient nucleation sites for UHMWPE molecules during their gel-spinning processes. These efficient nucleation sites of purified and acid treated ATP nanofibers then facilitate the crystallization of UHMWPE molecules into crystals with thinner lamellar thickness and/or lower $T_{m}$ values during their gel-spinning processes. Acid treated ATP nanofibers with even higher specific surface areas are likely to serve as more effective sites for nucleation of

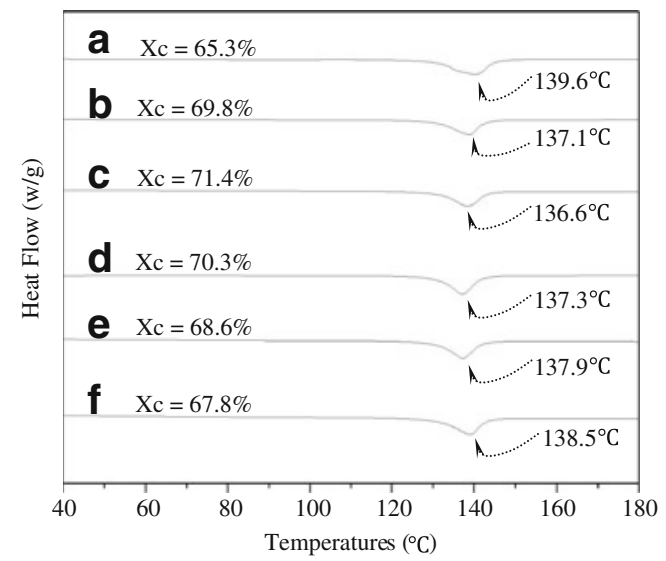

Fig. 6 DSC thermograms of a F100, b F100A1M-0.0125, c F100A1M0.025 , d F100A1M-0.05, e F100A1M-0.15, f F100A1M-0.25 as-prepared fiber specimens 


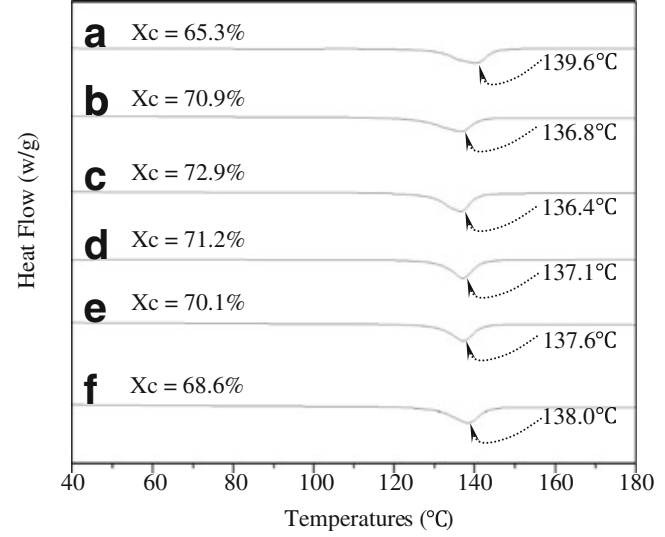

Fig. 7 DSC thermograms of a F100, b F100A2M-0.0125, c F100A2M0.025 , d F100A2M-0.05, e F100A2M-0.15, f F100A2M-0.25as-prepared fiber specimens

UHMWPE molecules than purified ATP nanofibers. As a consequence, $\mathrm{F}_{100} \mathrm{~A}_{5 \mathrm{M} \text {-y }}$ as-prepared fiber specimens exhibit significantly higher $\mathrm{X}_{\mathrm{c}}$ but lower $\mathrm{T}_{\mathrm{m}}$ and/or lamellar thickness values than the corresponding $\mathrm{F}_{100} \mathrm{~A}_{\mathrm{y}}$ and/or other $\mathrm{F}_{100} \mathrm{~A}_{\mathrm{xM}-\mathrm{y}}$ as-prepared fiber specimens with the same purified and/or acid treated ATP contents, respectively.

\section{Orientation factor}

Typical orientation factor $\left(f_{o}\right)$ values of $F_{100}, F_{100} A_{y}$ and $\mathrm{F}_{100} \mathrm{~A}_{\mathrm{xM}-\mathrm{y}}$ as-prepared and drawn fiber series specimens are summarized in Fig. 11. No significant difference in $\mathrm{f}_{\mathrm{o}}$ values was found for $F_{100}, F_{100} A_{y}$ and $F_{100} A_{x M-y}$ as-prepared fiber specimens. As expected, $f_{o}$ values of $F_{100}$ and each $F_{100} A_{y}$ or $\mathrm{F}_{100} \mathrm{~A}_{\mathrm{xM}-\mathrm{y}}$ fiber series specimens increase consistently as their draw ratios increase. After addition of purified and/or acid treated ATP nanofibers, the $f_{o}$ values of drawn $F_{100} A_{y}$ and/or $\mathrm{F}_{100} \mathrm{~A}_{\mathrm{xM}-\mathrm{y}}$ fiber specimens are significantly higher than those

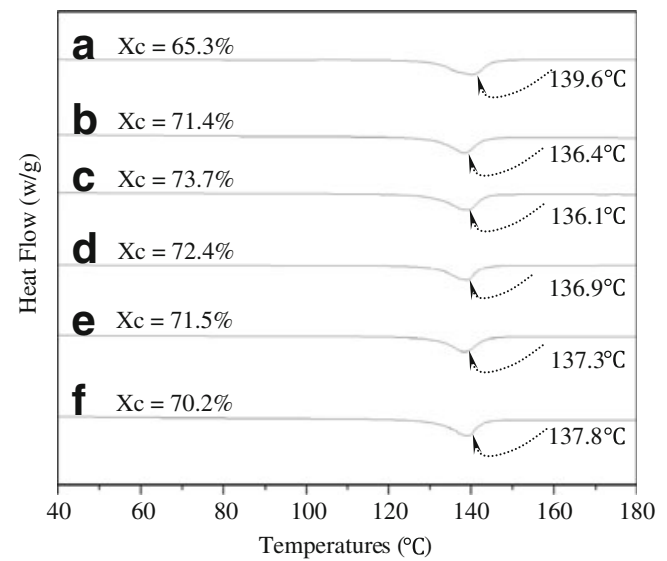

Fig. 8 DSC thermograms of a F100, b F100A3M-0.0125, c F100A3M0.025 , d F100A3M-0.05, e F100A3M-0.15, f F100A3M-0.25 as-prepared fiber specimens

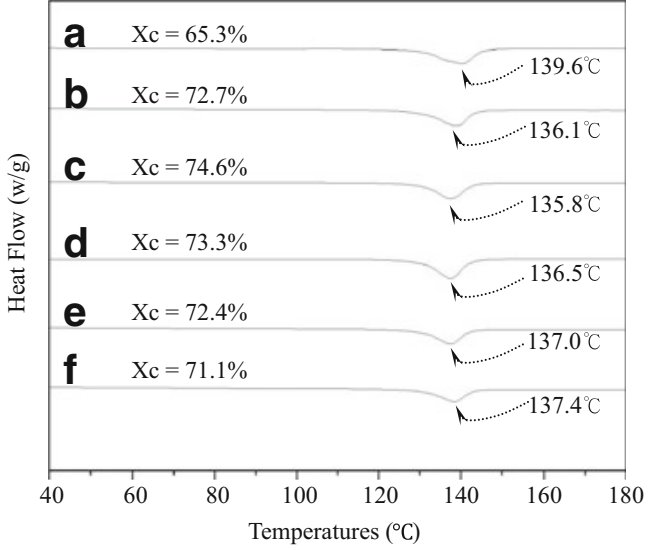

Fig. 9 DSC thermograms of a F100, b F100A5M-0.0125, c F100A5M0.025 , d F100A5M-0.05, e F100A5M-0.15, f F100A5M-0.25 as-prepared fiber specimens

of $F_{100}$ fiber specimens with the same draw ratios. The $f_{o}$ values of drawn $F_{100} A_{y}$ and $F_{100} A_{x M-y}$ fiber specimens with the same draw ratios reach a maximal value as their purified and acid treated ATP contents approach the optimal values at 0.05 and $0.025 \mathrm{phr}$, respectively. In which, $\mathrm{f}_{\mathrm{o}}$ values of drawn $\mathrm{F}_{100} \mathrm{~A}_{\mathrm{xM}-\mathrm{y}}$ fiber specimens are higher than those of the corresponding $\mathrm{F}_{100} \mathrm{~A}_{\mathrm{y}}$ fiber specimens with the same draw ratios and ATP contents but without treating with $\mathrm{HCl}$ solutions. Furthermore, it is worth to note that the $f_{o}$ values of drawn $\mathrm{F}_{100} \mathrm{~A}_{\mathrm{xM}-0.025}$ fiber specimens prepared at the optimal content of acid treated ATP nanofibers reach another maximal value as the $\mathrm{HCl}$ concentration and treating time approach the optimal value at $5 \mathrm{M}$ and $60 \mathrm{~min}$, respectively.

Achievable draw ratios of the as-prepared fiber specimens

Figure 12 summarized the achievable draw ratios $\left(\mathrm{D}_{\mathrm{ra}}\right)$ of the $\mathrm{F}_{100}, \mathrm{~F}_{100} \mathrm{~A}_{\mathrm{y}}$ and $\mathrm{F}_{100} \mathrm{~A}_{\mathrm{xM} \text {-y }}$ as-prepared fibers prepared at

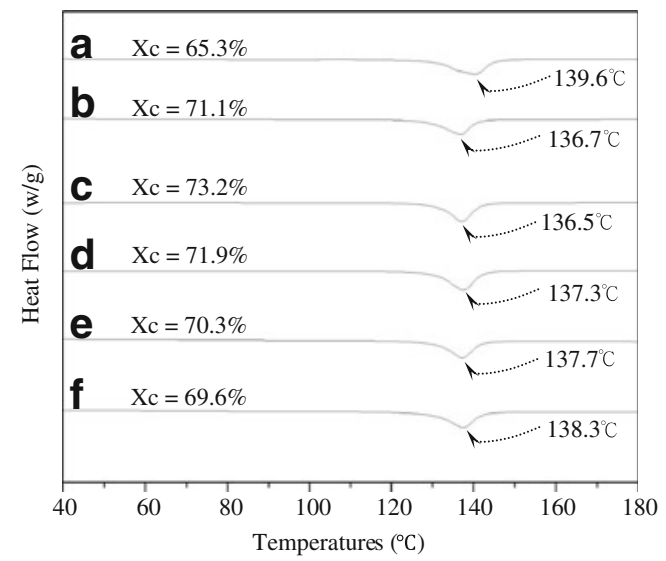

Fig. 10 DSC thermograms of a F100, b F100A7M-0.0125, c F100A7M-0.025, d F100A7M-0.05, e F100A7M-0.15, f F100A7M0.25 as-prepared fiber specimens 
Table 5 Melting temperatures and evaluated lamellar thickness values of UHMWPE as-prepared fiber specimens

\begin{tabular}{|c|c|c|c|}
\hline Samples & $\begin{array}{l}\mathrm{T}_{\mathrm{m}} \\
\left({ }^{\circ} \mathrm{C}\right)\end{array}$ & $\begin{array}{l}\sigma_{\mathrm{e}} \\
\left(10^{-7} \mathrm{~J} / \mathrm{cm}^{2}\right)\end{array}$ & $\begin{array}{l}1_{\mathrm{c}} \\
(\mathrm{nm})\end{array}$ \\
\hline $\mathrm{F}_{100}$ & 139.6 & 90.0 & 15.7 \\
\hline $\mathrm{F}_{100} \mathrm{~A}_{0.0125}$ & 138.1 & 90.0 & 12.6 \\
\hline $\mathrm{F}_{100} \mathrm{~A}_{0.025}$ & 137.5 & 90.0 & 11.6 \\
\hline $\mathrm{F}_{100} \mathrm{~A}_{0.05}$ & 137.4 & 90.0 & 11.5 \\
\hline $\mathrm{F}_{100} \mathrm{~A}_{0.15}$ & 138.6 & 90.0 & 13.5 \\
\hline $\mathrm{F}_{100} \mathrm{~A}_{0.25}$ & 139.4 & 90.0 & 15.2 \\
\hline $\mathrm{F}_{100} \mathrm{~A}_{1 \mathrm{M}-0.0125}$ & 137.1 & 90.0 & 11.1 \\
\hline $\mathrm{F}_{100} \mathrm{~A}_{1 \mathrm{M}-0.025}$ & 136.6 & 90.0 & 10.5 \\
\hline $\mathrm{F}_{100} \mathrm{~A}_{1 \mathrm{M}-0.05}$ & 137.3 & 90.0 & 11.3 \\
\hline $\mathrm{F}_{100} \mathrm{~A}_{1 \mathrm{M}-0.15}$ & 137.9 & 90.0 & 12.2 \\
\hline $\mathrm{F}_{100} \mathrm{~A}_{1 \mathrm{M}-0.25}$ & 138.5 & 90.0 & 13.3 \\
\hline $\mathrm{F}_{100} \mathrm{~A}_{2 \mathrm{M}-0.0125}$ & 136.8 & 90.0 & 10.7 \\
\hline $\mathrm{F}_{100} \mathrm{~A}_{2 \mathrm{M}-0.025}$ & 136.4 & 90.0 & 10.2 \\
\hline $\mathrm{F}_{100} \mathrm{~A}_{2 \mathrm{M}-0.05}$ & 137.1 & 90.0 & 11.1 \\
\hline $\mathrm{F}_{100} \mathrm{~A}_{2 \mathrm{M}-0.15}$ & 137.6 & 90.0 & 11.8 \\
\hline $\mathrm{F}_{100} \mathrm{~A}_{2 \mathrm{M}-0.25}$ & 138.0 & 90.0 & 12.4 \\
\hline $\mathrm{F}_{100} \mathrm{~A}_{3 \mathrm{M}-0.0125}$ & 136.4 & 90.0 & 10.2 \\
\hline $\mathrm{F}_{100} \mathrm{~A}_{3 \mathrm{M}-0.025}$ & 136.1 & 90.0 & 9.9 \\
\hline $\mathrm{F}_{100} \mathrm{~A}_{3 \mathrm{M}-0.05}$ & 136.9 & 90.0 & 10.8 \\
\hline $\mathrm{F}_{100} \mathrm{~A}_{3 \mathrm{M}-0.15}$ & 137.3 & 90.0 & 11.3 \\
\hline $\mathrm{F}_{100} \mathrm{~A}_{3 \mathrm{M}-0.25}$ & 137.8 & 90.0 & 12.1 \\
\hline $\mathrm{F}_{100} \mathrm{~A}_{5 \mathrm{M}-0.0125}$ & 136.1 & 90.0 & 9.9 \\
\hline $\mathrm{F}_{100} \mathrm{~A}_{5 \mathrm{M}-0.025}$ & 135.8 & 90.0 & 9.6 \\
\hline $\mathrm{F}_{100} \mathrm{~A}_{5 \mathrm{M}-0.05}$ & 136.5 & 90.0 & 10.3 \\
\hline $\mathrm{F}_{100} \mathrm{~A}_{5 \mathrm{M}-0.15}$ & 137.0 & 90.0 & 10.9 \\
\hline $\mathrm{F}_{100} \mathrm{~A}_{5 \mathrm{M}-0.25}$ & 137.4 & 90.0 & 11.5 \\
\hline $\mathrm{F}_{100} \mathrm{~A}_{7 \mathrm{M}-0.0125}$ & 136.7 & 90.0 & 10.6 \\
\hline $\mathrm{F}_{100} \mathrm{~A}_{7 \mathrm{M}-0.025}$ & 136.5 & 90.0 & 10.3 \\
\hline $\mathrm{F}_{100} \mathrm{~A}_{7 \mathrm{M}-0.05}$ & 137.3 & 90.0 & 11.3 \\
\hline $\mathrm{F}_{100} \mathrm{~A}_{7 \mathrm{M}-0.15}$ & 137.7 & 90.0 & 11.9 \\
\hline $\mathrm{F}_{100} \mathrm{~A}_{7 \mathrm{M}-0.25}$ & 138.3 & 90.0 & 12.9 \\
\hline
\end{tabular}

varying purified and acid treated ATP contents. Similar to those found in our previous study [41], $\mathrm{D}_{\mathrm{ra}}$ values of $\mathrm{F}_{100} \mathrm{~A}_{\mathrm{y}}$ as-prepared fibers are significantly higher than that of the $\mathrm{F}_{100}$ as-prepared fiber specimen without addition of purified ATP nanofibers. The $D_{r a}$ values of $F_{100} A_{y}$ as-prepared fiber series specimens increase significantly with the initial increase in purified ATP contents and then reach a maximal value at 145 as their purified ATP contents approach an optimal value at $0.05 \mathrm{phr}$. After treatment of $\mathrm{HCl}$ solutions on purified ATP nanofibers, the $D_{r a}$ values of each $F_{100} A_{x M-y}$ as-prepared fiber series specimens are significantly higher than those of the corresponding $\mathrm{F}_{100} \mathrm{~A}_{\mathrm{y}}$ as-prepared fiber specimens with the same purified ATP contents but without acid treatment. Similar to those found for $\mathrm{F}_{100} \mathrm{~A}_{\mathrm{y}}$ as-prepared fiber specimens, the $D_{\text {ra }}$ values of each $F_{100} A_{x M-y}$ as-prepared fiber series specimens reach a maximal value as their acid treated ATP contents approach a lower optimal value at $0.025 \mathrm{phr}$. Moreover, it is worth noting that the maximal $D_{\text {ra }}$ values of the $\mathrm{F}_{100} \mathrm{~A}_{\mathrm{xM}-0.025}$ as-prepared fiber specimens reached another maximal value as their purified ATP nanofibers were treated by $5 \mathrm{M} \mathrm{HCl}$ solutions for $60 \mathrm{~min}$. As shown in Fig. 12, the maximal $\mathrm{D}_{\mathrm{ra}}$ values obtained for $\mathrm{F}_{100} \mathrm{~A}_{5 \mathrm{M}-0.025}$ as-prepared fiber specimen reaches 249 , which is significantly higher than those of $\mathrm{F}_{100} \mathrm{~A}_{\mathrm{xM}-0.025}$ as-prepared fiber specimens prepared with $0.025 \mathrm{phr}$ ATP nanofibers treated with $\mathrm{HCl}$ concentrations other than $5 \mathrm{M}$.

As evidenced by thermal and lamellar thickness analyses, the $T_{m}$ and/or evaluated $l_{c}$ values of $F_{100} A_{y}$ and $F_{100} A_{x M-y}$ asprepared fiber specimens reduce significantly with the increase in purified and/or acid treated ATP contents, although the amounts of crystals with lower $T_{m}$ and/or evaluated $l_{c}$ values increase significantly as their purified and/or acid treated ATP contents increase. Presumably, these crystals with lower $T_{m}$ and/or evaluated $l_{c}$ values obtained at higher purified and/or acid treated ATP contents can be melted and pulled out of folded lamellar crystals relatively easily during ultradrawing processes, and hence, results in higher drawability and orientation of the $\mathrm{F}_{100} \mathrm{~A}_{\mathrm{y}}$ and $\mathrm{F}_{100} \mathrm{~A}_{\mathrm{xM}-\mathrm{y}}$ fibers. However, the amounts of coagulated and/or reticulated purified ATPs and/ or acid treated ATPs are likely to increase significantly when their ATPs contents are higher than certain values. These coagulated and/or reticulated purified ATPs and/or acid treated ATPs can slide with each other and serve as the defects during the drawing processes of $\mathrm{F}_{100} \mathrm{~A}_{\mathrm{y}}$ and $\mathrm{F}_{100} \mathrm{~A}_{\mathrm{xM} \text {-y }}$ as-prepared fiber specimens. The defects are likely to hinder the drawing and orientation of crystallites of the ultradrawn fibers along the drawing direction, and hence lead to a significant reduction in their achievable draw ratio and orientation factor values. Based on these premises, it is reasonable to understand that the achievable draw ratios of $\mathrm{F}_{100} \mathrm{~A}_{\mathrm{y}}$ and $\mathrm{F}_{100} \mathrm{~A}_{\mathrm{xM} \text {-y }}$ as-prepared fiber specimens and orientation factor values of the $F_{100} A_{y}$ and $\mathrm{F}_{100} \mathrm{~A}_{\mathrm{xM}-\mathrm{y}}$ fibers with a fixed draw ratio reduce significantly when their purified and/or acid treated ATP contents are higher than the specific optimal values.

Morphological analyses of the as-prepared and drawn fibers

Figure 13 show typical SEM micrographs of the as-prepared and drawn $\mathrm{F}_{100}, \mathrm{~F}_{100} \mathrm{~A}_{0.025}$ or $\mathrm{F}_{100} \mathrm{~A}_{5 \mathrm{M}-0.025}$ fiber specimens with various draw ratios. Many demarcated drawn "microfibrils" were found paralleling the drawing direction of the drawn $\mathrm{F}_{100}, \mathrm{~F}_{100} \mathrm{~A}_{0.025}$ or $\mathrm{F}_{100} \mathrm{~A}_{5 \mathrm{M}-0.025}$ fiber specimens as their draw ratios increase, wherein the thicknesses of these drawn micro-fibrils reduce significantly as the draw ratios increase. Moreover, it is worth noting that more and thinner "microfibrils" were found on the etched surfaces of $\mathrm{F}_{100} \mathrm{~A}_{5 \mathrm{M}-0.025}$ fiber specimen than those of $\mathrm{F}_{100} \mathrm{~A}_{0.025}$ and $\mathrm{F}_{100}$ fiber specimens with the same draw ratios, respectively. 
Fig. 11 The orientation factor (fo) values of F100 (+), F100A0.0125 (), F100A0.025 $(\diamond)$, F100A0.05 $(\triangle)$, F100A0.15 $(\times)$, F100A0.25 (०), F100A1M-

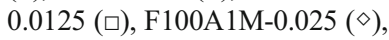
F100A1M-0.05 $(\triangle)$, F100A1M$0.15(\times)$, F100A1M-0.25 (०), F100A2M-0.0125 (口), F100A2M-0.025 (॰), F100A2M$0.05(\triangle)$, F100A2M-0.15 (×), F100A2M-0.25 (०), F100A3M-

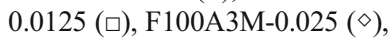
F100A3M-0.05 $(\triangle)$, F100A3M$0.15(\times)$, F100A3M-0.25 (०), F100A5M-0.0125 (), F100A5M-0.025 (॰), F100A5M$0.05(\triangle)$, F100A5M-0.15 (×), F100A5M-0.25 (O), F100A7M-

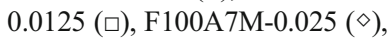
F100A7M-0.05 $(\triangle)$, F100A7M$0.15(\times)$, F100A7M-0.25 (०) asprepared and drawn fiber specimens with varying draw ratios

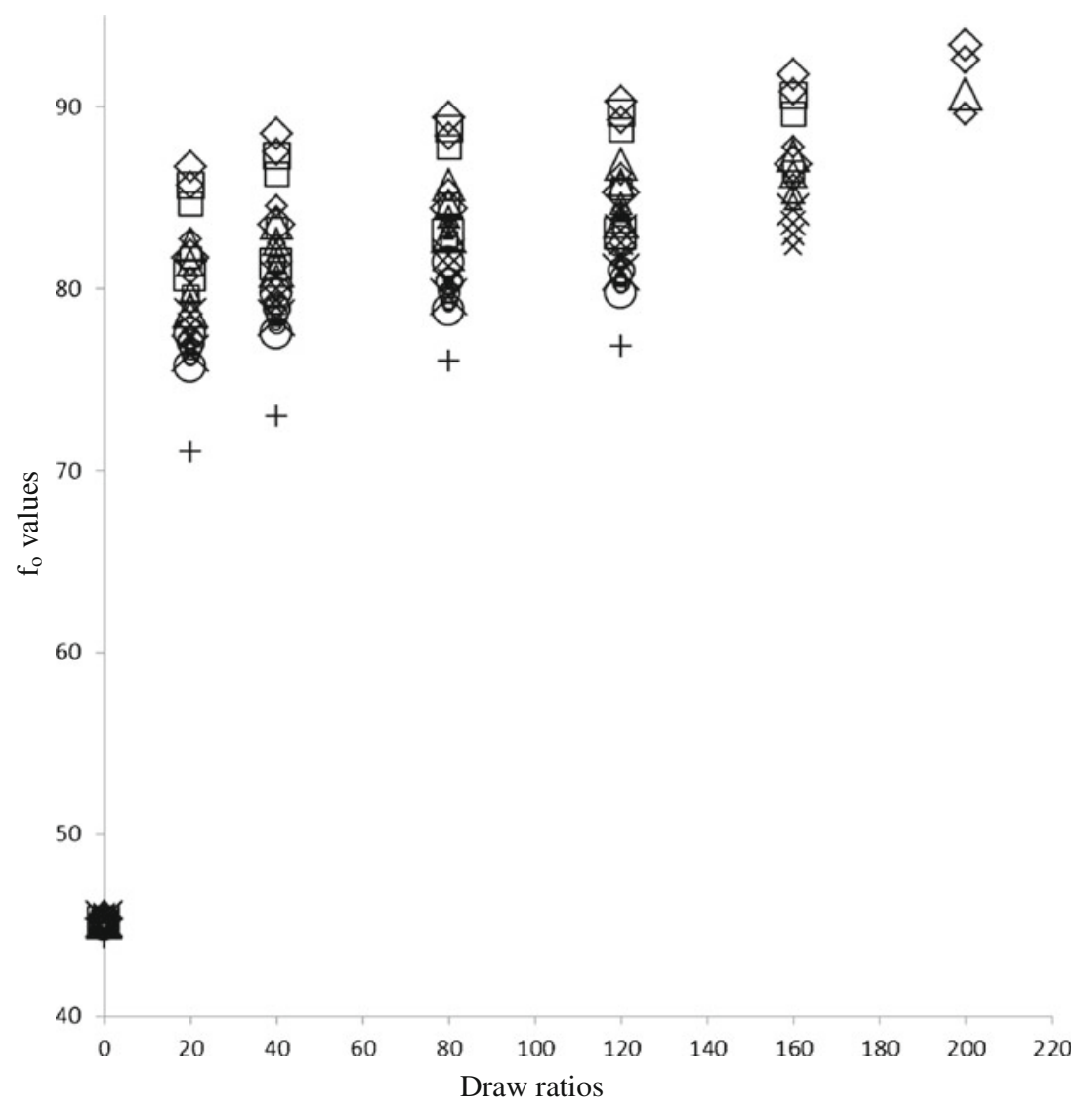

It is not completely clear what accounts for the interesting demarcated "micro-fibril" morphology found in the $\mathrm{F}_{100}$, $\mathrm{F}_{100} \mathrm{~A}_{0.025}$ or $\mathrm{F}_{100} \mathrm{~A}_{5 \mathrm{M}-0.025}$ drawn fiber specimens. Presumably, during the ultra-drawing processes, many of the UHMWPE kebab crystals with relatively thinner lamellar thickness values can be unfolded and pulled out of the crystal lamellae in an easier way than those kebab crystals with thicker lamellar thickness values. The unfolded UHMWPE molecules pulled out from the kebab lamellae can then gradually transform into the oriented "micro-fibrils" during their

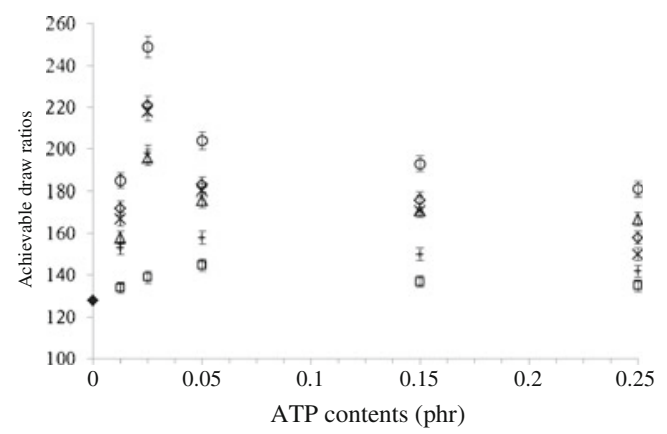

Fig. 12 Achievable draw ratios of F100 (•), F100Ay ( $\square)$, F100A1M-y $(\triangle)$, F100A2M-y $(\times)$, F100A3M-y $(\diamond)$, F100A5M-y (०) and F100S7M-y $(+)$ as-prepared fiber specimens ultra-drawing processes. As evidenced by DSC analysis in the previous section, the $T_{m}$ and/or evaluated $l_{c}$ values of $F_{100} A_{y}$ and $\mathrm{F}_{100} \mathrm{~A}_{\mathrm{xM} \text {-y }}$ as-prepared fiber series specimens reduce significantly as their purified ATP and/or acid treated ATP contents increase. In which, crystals with rather low $T_{m}$ and evaluated $l_{c}$ values were found for $F_{100} A_{x M-y}$ fiber specimens than those of the corresponding $\mathrm{F}_{100} \mathrm{~A}_{\mathrm{y}}$ with the same ATP contents but without acid treatment. It is, therefore, reasonable to understand that the "micro-fibrils" found on the etched surfaces of drawn $\mathrm{F}_{100} \mathrm{~A}_{5 \mathrm{M}-0.025}$ and $\mathrm{F}_{100} \mathrm{~A}_{0.025}$ fiber specimens are more and thinner than those of the corresponding drawn $\mathrm{F}_{100}$ fiber specimens with the same draw ratios. In which, more and thinner "micro-fibrils" were found on the etched surfaces of $\mathrm{F}_{100} \mathrm{~A}_{5 \mathrm{M}-0.025}$ fiber specimen than those of $\mathrm{F}_{100} \mathrm{~A}_{0.025}$ and $\mathrm{F}_{100}$ fiber specimens with the same draw ratios.

Tensile properties

The tensile properties of $\mathrm{F}_{100}, \mathrm{~F}_{100} \mathrm{~A}_{\mathrm{y}}$ and $\mathrm{F}_{100} \mathrm{~A}_{\mathrm{xM}-\mathrm{y}}$ series fiber series specimens prepared at varying draw ratios are illustrated in Figs. 14 and 15 (Table 6). As expected, the tensile strength $\left(\sigma_{\mathrm{f}}\right)$ and modulus $(\mathrm{E})$ values of the drawn $F_{100}, F_{100} A_{y}$ and $F_{100} A_{x M-y}$ fiber series specimens improve consistently as their draw ratios increase. Similar to those found for their orientation factors, the $\sigma_{\mathrm{f}}$ and $\mathrm{E}$ values of both 
Fig. 13 SEM micrographs of the F100 fiber specimens with a draw ratio of a $1, \mathbf{b} 50, \mathbf{c} 100$; and of the F100A0.025 fiber specimens with a draw ratio of $\mathbf{d} 1$, e $50, \mathbf{f}$ 100; and of the F100A5M-0.025 fiber specimens with a draw ratio of $\mathbf{g} 1, \mathbf{h} 50, \mathbf{i} 100$
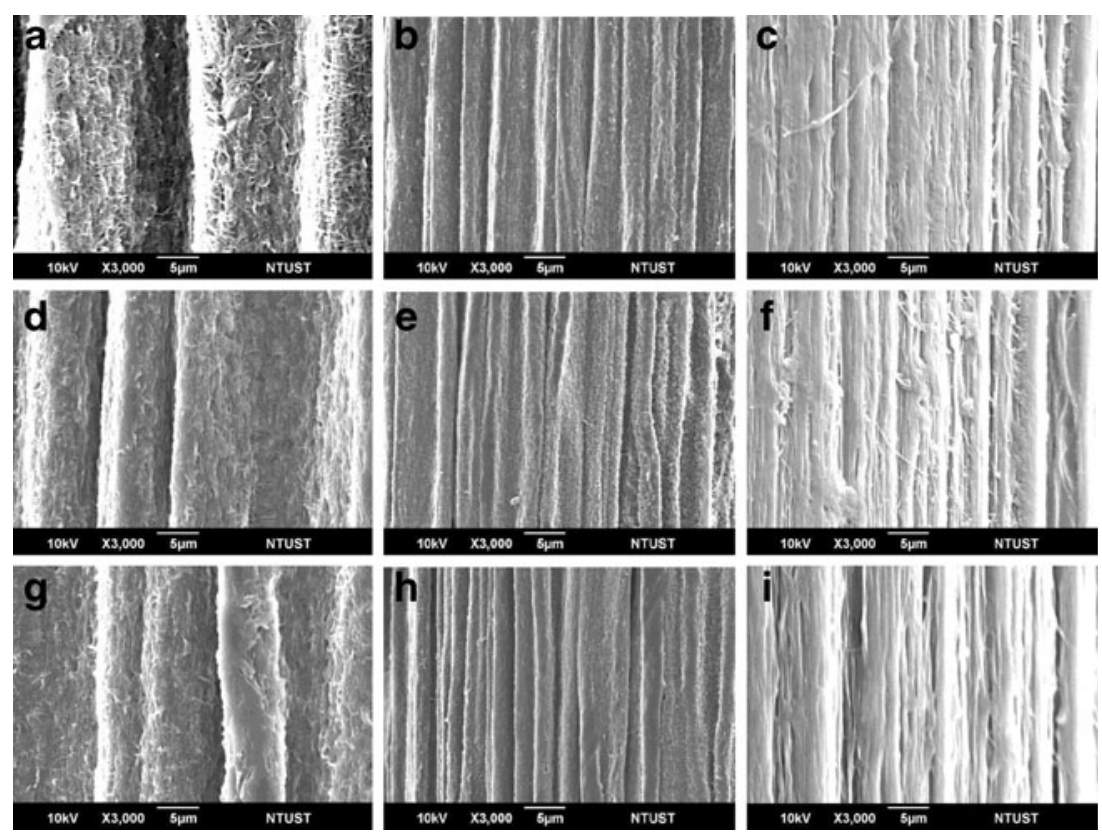

drawn $\mathrm{F}_{100} \mathrm{~A}_{\mathrm{y}}$ and $\mathrm{F}_{100} \mathrm{~A}_{\mathrm{xM}-\mathrm{y}}$ fiber series specimens with a fixed draw ratio reach a maximal value as their purified and/or acid treated ATP contents approach the optimal values at 0.05 and $0.025 \mathrm{phr}$, respectively, wherein the $\sigma_{\mathrm{f}}$ and $\mathrm{E}$ values of the
$\mathrm{F}_{100} \mathrm{~A}_{\mathrm{xM}-\mathrm{y}}$ fiber specimens are always significantly higher than those of the corresponding $\mathrm{F}_{100} \mathrm{~A}_{\mathrm{y}}$ fiber specimens prepared at the same draw ratios and ATP contents but without acid treatment.
Fig. 14 The tensile strengh values of F100 (+), F100A0.0125 (口), F100A0.025 (॰), F100A0.05 $(\triangle)$, F100A0.15 (×), F100A0.25 (०), F100A1M-0.0125 (口), F100A1M-0.025 (॰), F100A1M$0.05(\triangle)$, F100A1M-0.15 (×), F100A1M-0.25 (०), F100A2M-

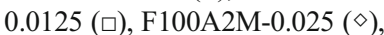
F100A2M-0.05 $(\triangle)$, F100A2M$0.15(\times)$, F100A2M-0.25 (०), F100A3M-0.0125 (口), F100A3M-0.025 (॰), F100A3M$0.05(\triangle)$, F100A3M-0.15 (×), F100A3M-0.25 (०), F100A5M-

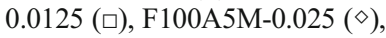
F100A5M-0.05 $(\triangle)$, F100A5M$0.15(\times)$, F100A $5 \mathrm{M}-0.25$ (०), F100A7M-0.0125 (口), F100A7M-0.025 (๖), F100A7M$0.05(\triangle)$, F100A7M-0.15 $(\times)$, F100A7M-0.25 (o) fiber specimens with varying draw ratios

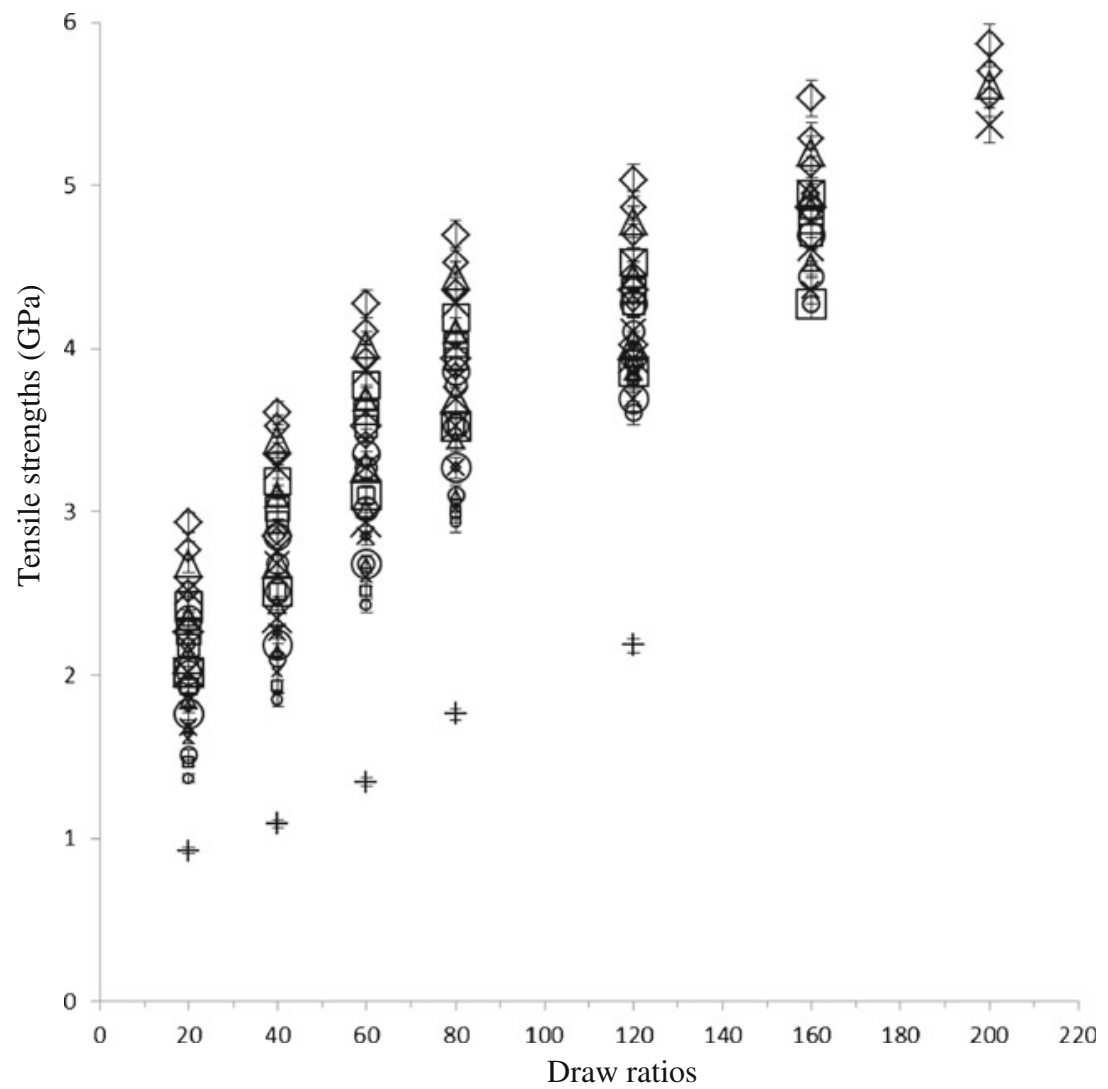


Fig. 15 The modulus values of F100 (+), F100A0.0125 (口),

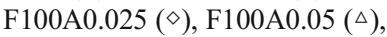
F100A0.15 (×), F100A0.25 (०), F100A1M-0.0125 (口), F100A1M-0.025 (॰), F100A1M$0.05(\triangle)$, F100A1M-0.15 $(\times)$, F100A1M-0.25 (०), F100A2M-

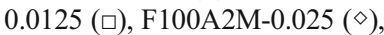
F100A2M-0.05 $(\triangle)$, F100A2M$0.15(\times)$, F100A2M-0.25 (०), F100A3M-0.0125 (), F100A3M-0.025 (॰), F100A3M$0.05(\triangle)$, F100A3M-0.15 (×), F100A3M-0.25 (०), F100A5M-

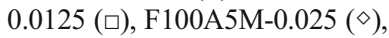
F100A5M-0.05 $(\triangle)$, F100A5M$0.15(\times)$, F100A5M-0.25 (०), F100A7M-0.0125 (口), F100A7M-0.025( $\diamond)$, F100A7M$0.05(\triangle)$, F100A7M-0.15 $(\times)$, F100A7M-0.25 (०) fiber specimens with varying draw ratios

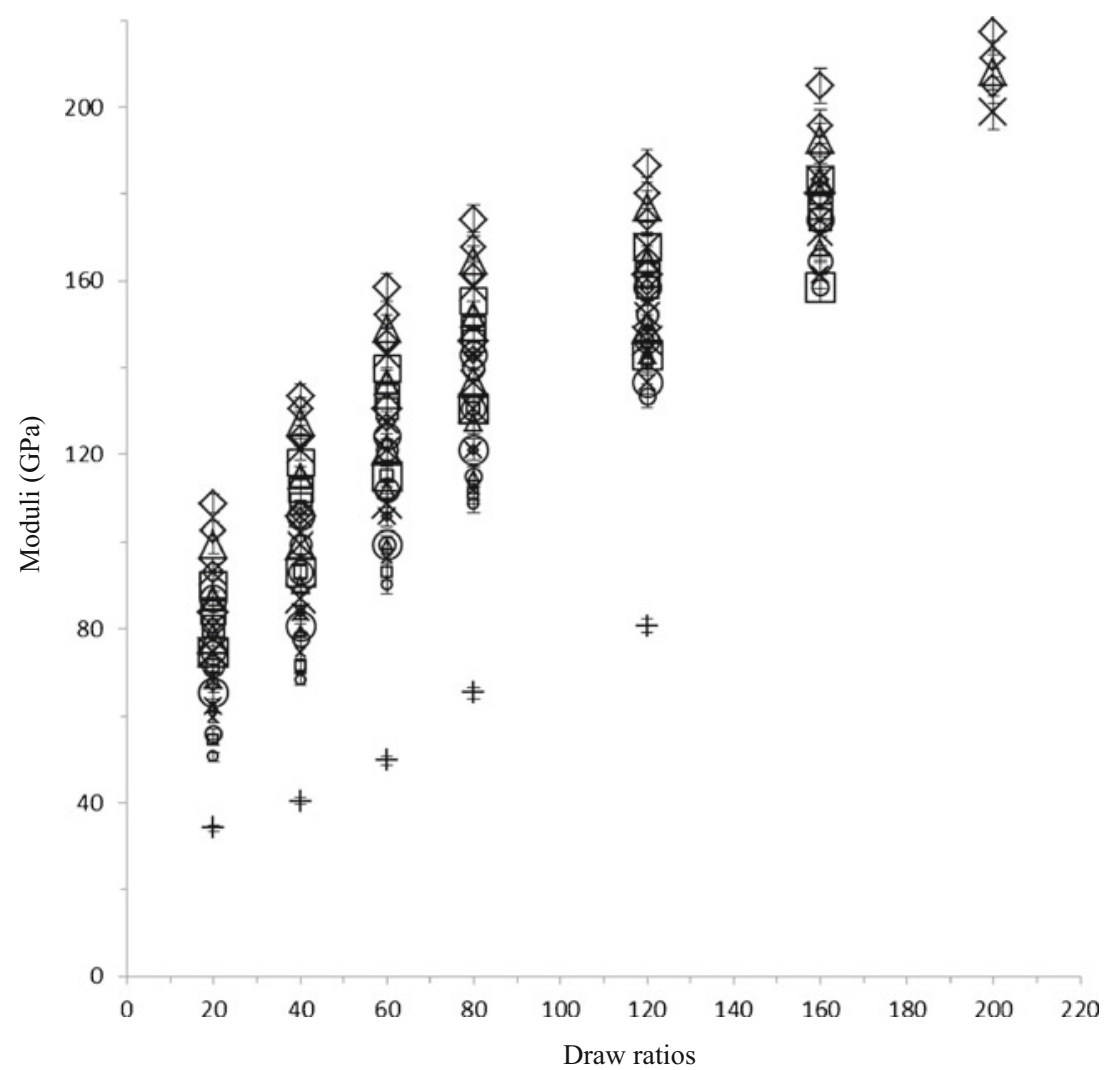

The mechanical properties of the drawn specimens are generally believed to depend mainly on the degree of orientation of the drawn specimens, as their molecular weights are constant $[48,49]$. As evidenced by the orientation analysis, at a fixed draw ratio, the orientation factor values of the drawn $\mathrm{F}_{100} \mathrm{~A}_{0.05}$ and $\mathrm{F}_{100} \mathrm{~A}_{\mathrm{xM}-0.025}$ fiber specimens prepared at the optimal purified and acid treated ATP contents are always higher than those of other $\mathrm{F}_{100} \mathrm{~A}_{\mathrm{y}}$ and/or $\mathrm{F}_{100} \mathrm{~A}_{\mathrm{xM}-\mathrm{y}}$ fiber specimens prepared at ATP and/or acid treated ATP contents deviating from their optimal values, respectively. In which, the orientation factor values of the $\mathrm{F}_{100} \mathrm{~A}_{\mathrm{xM}-0.025}$ fiber specimens are always higher than those of the corresponding $\mathrm{F}_{100} \mathrm{~A}_{0.05}$ fiber specimens with the same draw ratios and ATP contents but without acid treatment. These results clearly suggest that a good orientation of UHMWPE molecules along the drawing direction positively affects the tensile properties of the $\mathrm{F}_{100} \mathrm{~A}_{\mathrm{y}}$ and $\mathrm{F}_{100} \mathrm{~A}_{\mathrm{xM} \text {-y }}$ fibers. Excellent orientation and tensile properties of the UHMWPE fibers can be prepared by ultradrawing the $\mathrm{F}_{100} \mathrm{~A}_{0.05}$ and $\mathrm{F}_{100} \mathrm{~A}_{\mathrm{xM}-0.025}$ as-prepared fibers prepared at the optimal purified and/or acid treated ATP contents, respectively, in which, significant better orientation and tensile properties can be obtained for $\mathrm{F}_{100} \mathrm{~A}_{\mathrm{xM}-0.025}$ fiber specimens with even higher specific surface areas of acid treated ATP nanafibers.

\section{Conclusions}

The rodlike feature of acid treated ATP nanofibers were significantly etched into broken/shorter and thinner nanofibers by $\mathrm{HCl}$ solutions as their concentrations increase. In fact, after etching by $7 \mathrm{M} \mathrm{HCl}$ solution for $60 \mathrm{~min}$, nearly only broken/ short ATP nanofibers were found for $A_{7 M}$ specimen. Similarly, $A_{5 M}$ specimens were etched into broken/shorter and thinner rodlike feature as the treating time increased from 20 to $100 \mathrm{~min}$. In which, nearly only broken and short ATP nanofibers were found for $A_{5 \mathrm{M}}$ specimens after they were excessive etched for more than $60 \mathrm{~min}$. The specific surface area of the purified ATP specimen is relatively high at $205 \mathrm{~m}^{2} / \mathrm{g}$. The specific surface areas of each acid treated ATP series specimens reach a maximal value as the treating time approaches an appropriate value at $60 \mathrm{~min}$. The maximal specific surface areas obtained for acid treated ATP specimens reach another maximal value at $282 \mathrm{~m}^{2} / \mathrm{g}$ as the $\mathrm{HCl}$ concentrations used for $60 \mathrm{~min}$ of acid treatment approach an optimal value at $5 \mathrm{M}$. The $\mathrm{T}_{\mathrm{m}}$ (or evaluated $\mathrm{l}_{\mathrm{c}}$ ) and $\mathrm{X}_{\mathrm{c}}$ values of $\mathrm{F}_{100} \mathrm{~A}_{\mathrm{y}}$ and/or $\mathrm{F}_{100} \mathrm{~A}_{\mathrm{xM} \text {-y }}$ asprepared fiber series specimens approach the minimal and maximal values, as their purified and/or acid treated ATP approach the optimal values at 0.05 and $0.025 \mathrm{phr}$, respectively. In which, $\mathrm{T}_{\mathrm{m}}$ (or evaluated $\mathrm{l}_{\mathrm{c}}$ ) and $\mathrm{X}_{\mathrm{c}}$ values of the $\mathrm{F}_{100} \mathrm{~A}_{\mathrm{xM}-\mathrm{y}}$ asprepared fiber specimens are significantly lower and higher 
Table 6 Tensile strength $\left(\sigma_{\mathrm{f}}\right)$ and modulus values (E) of UHMWPE drawn fiber specimens

\begin{tabular}{|c|c|c|c|c|c|c|c|c|c|c|}
\hline \multirow{2}{*}{$\begin{array}{l}\text { Specimen } \\
\text { Draw ratio }\end{array}$} & \multicolumn{2}{|l|}{$\mathrm{F}_{100}$} & \multicolumn{2}{|c|}{$\mathrm{F}_{100} \mathrm{~A}_{0.0125}$} & \multicolumn{2}{|c|}{$\mathrm{F}_{100} \mathrm{~A}_{0.025}$} & \multicolumn{2}{|c|}{$\mathrm{F}_{100} \mathrm{~A}_{0.25}$} & \multicolumn{2}{|c|}{$\mathrm{F}_{100} \mathrm{~A}_{1 \mathrm{M}-0.0125}$} \\
\hline & $\sigma_{\mathrm{f}}(\mathrm{GPa})$ & $\mathrm{E}(\mathrm{GPa})$ & $\sigma_{\mathrm{f}}(\mathrm{GPa})$ & $\mathrm{E}(\mathrm{GPa})$ & $\sigma_{\mathrm{f}}(\mathrm{GPa})$ & $\mathrm{E}(\mathrm{GPa})$ & $\sigma_{\mathrm{f}}(\mathrm{GPa})$ & $\mathrm{E}(\mathrm{GPa})$ & $\sigma_{\mathrm{f}}(\mathrm{GPa})$ & $\mathrm{E}(\mathrm{GPa})$ \\
\hline 20 & 0.9 & 34.2 & 1.5 & 54.3 & 1.8 & 66.8 & 1.4 & 50.6 & 1.9 & 71.4 \\
\hline 40 & 1.1 & 40.4 & 1.9 & 71.4 & 2.3 & 83.8 & 1.8 & 68.3 & 2.5 & 93.2 \\
\hline 60 & 1.3 & 49.7 & 2.5 & 93.2 & 2.9 & 105.6 & 2.4 & 90.1 & 3.1 & 114.9 \\
\hline \multirow[t]{3}{*}{120} & 2.2 & 80.7 & 3.8 & 141.0 & 4.0 & 149.1 & 3.8 & 141.6 & 3.9 & 146.0 \\
\hline & \multicolumn{2}{|c|}{$\mathrm{F}_{100} \mathrm{~A}_{1 \mathrm{M}-0.025}$} & \multicolumn{2}{|c|}{$\mathrm{F}_{100} \mathrm{~A}_{1 \mathrm{M}-0.25}$} & \multicolumn{2}{|c|}{$\mathrm{F}_{100} \mathrm{~A}_{2 \mathrm{M}-0.0125}$} & \multicolumn{2}{|c|}{$\mathrm{F}_{100} \mathrm{~A}_{2 \mathrm{M}-0.025}$} & \multicolumn{2}{|c|}{$\mathrm{F}_{100} \mathrm{~A}_{2 \mathrm{M}-0.25}$} \\
\hline & $\sigma_{\mathrm{f}}(\mathrm{GPa})$ & $\mathrm{E}(\mathrm{GPa})$ & $\sigma_{\mathrm{f}}(\mathrm{GPa})$ & $\mathrm{E}(\mathrm{GPa})$ & $\sigma_{\mathrm{f}}(\mathrm{GPa})$ & $\mathrm{E}(\mathrm{GPa})$ & $\sigma_{\mathrm{f}}(\mathrm{GPa})$ & $\mathrm{E}(\mathrm{GPa})$ & $\sigma_{\mathrm{f}}(\mathrm{GPa})$ & $\mathrm{E}(\mathrm{GPa})$ \\
\hline 20 & 2.2 & 80.7 & 1.5 & 55.9 & 2.2 & 80.7 & 2.5 & 93.2 & 1.9 & 71.4 \\
\hline 40 & 2.9 & 105.6 & 2.1 & 77.6 & 2.9 & 108.7 & 3.4 & 124.2 & 2.7 & 99.4 \\
\hline 60 & 3.4 & 127.3 & 2.7 & 99.4 & 3.5 & 130.4 & 3.9 & 146.0 & 3.3 & 121.1 \\
\hline 120 & 4.3 & 158.4 & 3.6 & 133.5 & 4.3 & 158.4 & 4.7 & 173.9 & 4.1 & 152.2 \\
\hline \multirow[t]{3}{*}{160} & 4.9 & 183.2 & 4.3 & 158.4 & 4.7 & 173.9 & 5.1 & 189.4 & - & - \\
\hline & \multicolumn{2}{|c|}{$\mathrm{F}_{100} \mathrm{~A}_{3 \mathrm{M}-0.0125}$} & \multicolumn{2}{|c|}{$\mathrm{F}_{100} \mathrm{~A}_{3 \mathrm{M}-0.025}$} & \multicolumn{2}{|c|}{$\mathrm{F}_{100} \mathrm{~A}_{3 \mathrm{M}-0.25}$} & \multicolumn{2}{|c|}{$\mathrm{F}_{100} \mathrm{~A}_{5 \mathrm{M}-0.0125}$} & \multicolumn{2}{|c|}{$\mathrm{F}_{100} \mathrm{~A}_{5 \mathrm{M}-0.025}$} \\
\hline & $\sigma_{\mathrm{f}}(\mathrm{GPa})$ & $\mathrm{E}(\mathrm{GPa})$ & $\sigma_{\mathrm{f}}(\mathrm{GPa})$ & $\mathrm{E}(\mathrm{GPa})$ & $\sigma_{\mathrm{f}}(\mathrm{GPa})$ & $\mathrm{E}(\mathrm{GPa})$ & $\sigma_{\mathrm{f}}(\mathrm{GPa})$ & $\mathrm{E}(\mathrm{GPa})$ & $\sigma_{\mathrm{f}}(\mathrm{GPa})$ & $\mathrm{E}(\mathrm{GPa})$ \\
\hline 20 & 2.3 & 83.8 & 2.8 & 102.5 & 2.0 & 74.5 & 2.4 & 90.1 & 2.9 & 108.7 \\
\hline 40 & 3.0 & 111.8 & 3.5 & 130.4 & 2.5 & 93.2 & 3.2 & 118.0 & 3.6 & 133.5 \\
\hline 60 & 3.6 & 133.5 & 4.1 & 152.2 & 3.0 & 111.8 & 3.8 & 139.7 & 4.3 & 158.4 \\
\hline 120 & 4.4 & 161.5 & 4.9 & 180.1 & 3.9 & 146.0 & 4.5 & 167.7 & 5.0 & 186.3 \\
\hline \multirow[t]{3}{*}{160} & 4.8 & 177.0 & 5.3 & 195.6 & 4.4 & 164.6 & 4.9 & 183.2 & 5.5 & 205.0 \\
\hline & \multicolumn{2}{|c|}{$\mathrm{F}_{100} \mathrm{~A}_{5 \mathrm{M}-0.25}$} & \multicolumn{2}{|c|}{$\mathrm{F}_{100} \mathrm{~A}_{7 \mathrm{M}-0.0125}$} & \multicolumn{2}{|c|}{$\mathrm{F}_{100} \mathrm{~A}_{7 \mathrm{M}-0.025}$} & \multicolumn{2}{|c|}{$\mathrm{F}_{100} \mathrm{~A}_{7 \mathrm{M}-0.25}$} & - & \\
\hline & $\sigma_{\mathrm{f}}(\mathrm{GPa})$ & $\mathrm{E}(\mathrm{GPa})$ & $\sigma_{\mathrm{f}}(\mathrm{GPa})$ & $\mathrm{E}(\mathrm{GPa})$ & $\sigma_{\mathrm{f}}(\mathrm{GPa})$ & $\mathrm{E}(\mathrm{GPa})$ & $\sigma_{\mathrm{f}}(\mathrm{GPa})$ & $\mathrm{E}(\mathrm{GPa})$ & - & \\
\hline 20 & 2.3 & 87.0 & 2.0 & 74.5 & 2.3 & 83.8 & 1.8 & 65.2 & - & \\
\hline 40 & 2.9 & 105.6 & 2.5 & 93.2 & 2.9 & 105.6 & 2.2 & 80.7 & - & \\
\hline 60 & 3.4 & 124.2 & 3.1 & 114.9 & 3.5 & 130.4 & 2.7 & 99.4 & - & \\
\hline 120 & 4.3 & 158.4 & 3.9 & 142.9 & 4.4 & 161.5 & 3.7 & 136.6 & & \\
\hline 160 & 4.7 & 173.9 & 4.3 & 158.4 & 4.9 & 180.1 & - & - & - & \\
\hline
\end{tabular}

than those of the corresponding $\mathrm{F}_{100} \mathrm{~A}_{\mathrm{y}}$ as-prepared fiber specimens with the same ATP contents but without acid treatment, respectively. Moreover, it is worth noting that each $\mathrm{F}_{100} \mathrm{~A}_{5 \mathrm{M}-\mathrm{y}}$ as-prepared fiber series specimen exhibits the lowest $T_{m}$ (or evaluated $l_{c}$ ) but the highest $X_{c}$ values among $F_{100} A_{x M-y}$ asprepared fiber series specimens with the same contents of acid treated ATP nanofibers treating with different $\mathrm{HCl}$ concentrations for $60 \mathrm{~min}$. Apparently, the efficient nucleation sites of purified and acid treated ATP nanofibers facilitate the crystallization of UHMWPE molecules into crystals with lower $T_{m}$ (or evaluated $1_{c}$ ) values during their gel-spinning processes. Acid treated ATP nanofibers with higher specific surface areas appear to serve as more effective sites for nucleation of UHMWPE molecules than purified ATP nanofibers.

In a way similar to those found for the orientation factor values, the achievable draw ratios of the $\mathrm{F}_{100} \mathrm{~A}_{\mathrm{y}}$ and $\mathrm{F}_{100} \mathrm{~A}_{\mathrm{xM}-\mathrm{y}}$ as-prepared fibers and tensile strength values of their drawn fibers approach a maximal value as their purified ATP and/or acid treated ATP contents reach the optimal values at 0.05 and $0.025 w t \%$, respectively. The maximal $\mathrm{D}_{\mathrm{ra}}$ values of $\mathrm{F}_{100} \mathrm{~A}_{\mathrm{xM}-0.025}$ as-prepared series fiber specimens and the tensile strengths and moduli of the drawn $\mathrm{F}_{100} \mathrm{~A}_{\mathrm{xM}-0.025}$ fiber specimens are significantly higher than those of the $\mathrm{F}_{100} \mathrm{~A}_{0.05}$ drawn fiber specimens prepared at the same draw ratios and optimal ATP contents but without acid treatment. Moreover, it is worth noting that the maximal $\mathrm{D}_{\mathrm{ra}}$ values of the $\mathrm{F}_{100} \mathrm{~A}_{\mathrm{xM}-0.025}$ as-prepared fiber specimens and the tensile strengths and moduli of the drawn $\mathrm{F}_{100} \mathrm{~A}_{\mathrm{xM}-0.025}$ fiber specimens reached another maximal value as their ATP nanofibers were treated by $5 \mathrm{M} \mathrm{HCl}$ solutions for $60 \mathrm{~min}$. Morphological analyses revealed that more and thinner "micro-fibrils" were present on the etched surfaces of $\mathrm{F}_{100} \mathrm{~A}_{5 \mathrm{M}-0.025}$ fiber specimen than those of $F_{100} A_{0.025}$ and $F_{100}$ fiber specimens with the same draw ratios, respectively. The above results suggest that excellent orientation and ultimate tensile properties of UHMWPE fibers can be obtained by ultradrawing the $\mathrm{F}_{100} \mathrm{~A}_{\mathrm{xM}-0.025}$ asprepared fibers prepared at the optimal contents of acid treated ATP nanofibers treated with proper condition. 
Acknowledgments The authors would like to express their appreciation to the Department of Industrial Technology, Ministry of Economic Affairs (95-EC-17-A-11-S1-057, 96-EC-17-A-11-S1-057, 97-EC-17-A-11-S1057, 99-EC-17-A-11-S1-155 and 100-EC-17-A-11-S1-155) and National Science Council (NSC 95-2221-E-253 -008 -MY3 and NSC 99-2221-E011-010-MY3) for support of this work.

Open Access This article is distributed under the terms of the Creative Commons Attribution License which permits any use, distribution, and reproduction in any medium, provided the original author(s) and the source are credited.

\section{References}

1. Zwijnenburg A, Pennings A (1975) Colloid Polym Sci 253:452

2. Smith P, Lemstra PJ (1979) Macromol Chem 180:2983

3. Smith P, Lemstra JP, Pijpers L, Kiel AM (1981) Colloid Polym Sci 259:1070

4. Ohta T, Okada F (1987) U. S. Patent 4643865

5. Ohta T, Okada F, Hayashi M, Mihoichi M (1989) Polymer 30:2170

6. Furuhata K, Yokokawa T, Ohsawa K, Miyasaka K (1983) Polym Prepr Jpn 32:874

7. Kanamoto T, Ooki T, Tanaka K, Takeda M (1983) Polym Prepr Jpn 32:741

8. Smith P, Chanzy HD, Rotzinger BP (1985) Polym Commun 26:258

9. Chanzy HD, Rotzinger BP, Smith P (1987) Patent WO-8703288

10. Smith P, Chanzy HD, Rotzinger BP (1987) J Mater Sci 22:523

11. Kanamoto T, Ohama T, Tanaka K, Takeda M, Porter RS (1987) Polymer 28:1517

12. Sawatari C, Okumura T, Matsuo M (1986) Polymer J 18:741

13. Darras D, Sequela R, Rietsch F (1992) J Polym Sci Polym Phys Ed 30:349

14. Yeh JT, Lin YL, Fan-Chiang CC (1996) Macromol Chem Phys 197:3531

15. Yeh JY, Wu HC (1998) Polym J 30:1

16. Yeh JT, Chang SS, Yen MS (1998) J Appl Polym Sci 70:149

17. Yeh JT, Chang SS (2000) J Mater Sci 35:3227

18. Smith P, Lemstra PJ (1980) J Mater Sci 15:505

19. Yeh JT, Chang SS (2002) Polym Eng Sci 42:1558
20. Jiang T, Yeh JT, Lin YT, Chen KN (2003) Polym Eng Sci 43:1765

21. Matsuo M, Sawatari C, Iida M, Yoneda M (1985) Polym J 17:1197

22. Kanamoto T, Tsurta A, Tanana K, Takeda M, Porter RS (1988) Macromolecules 21:470

23. Smook J, Pennings AJ (1982) J Appl Poly Sci 27:2209

24. Prevorsek DC (1982) Polymer liquid crystals, Academic Press. pp 357

25. Kalb B, Pennings AJ (1980) Polymer 21:3

26. Wilding MA, Word IM (1978) Polymer 19:969

27. Smith P, Lemstra PJ (1980) Polymer 21:1341

28. Kavesh S, Prevorsek DC (1985) U.S. Patent 4536536

29. Kavesh S, Prevorsek DC, U.S. Patent 4551296 (1985)

30. Kavesh S, Prevorsek DC (1983) U.S. Patent 4413110

31. Yeh JT, Wu ZW, Lai YC, Li QC, Zhou HP, Zhou Q, Shu YC, Huang CY (2011) Pom Eng Sci 51:2552

32. Yeh JT, Wu TW, Lai YC, Zhou HP, Zhou Q, Li QC, Tsai FC, Huang CY, Huang KS, Chen KN (2011) Polym Eng Sci 51:687

33. Yeh JT, Lin SC, Chen KN, Huang KS (2008) J Appl Polym Sci 110:2538

34. Yeh JT, Lai YC, Hai L, Yao CS, Chi YN, Kuo SH, Kan NC (2011) Polym Int 60:59

35. Yeh JT, Du CW, Lin SC, Hsie KH, Chang FC (2008) J Mater Sci 43:4892

36. Bradley WF (1940) Am Mineral 25:405

37. Frost RL, Cash GA, Kloprogge JT (1998) Vib Spectrc 16(2):173

38. Christ, Hathaway CL (1969) Am Mineral 54:198

39. Drits, Sokolova VA (1971) Sov Phys Crystallogr 16:183

40. Yamaura K, Tanigami T, Hayashi N, Kosuda KI, Okuda S, Takemura Y, Itoh M, Matsuzawa S (1990) J Appl Polym Sci 40:905

41. Yeh JT, Wang CK, Hu P, Lai YC, Hai L, Tsai FC (2012) Polym Int 6:982

42. Kajiwara K, Mcintyre JE (1994) Advanced fiber spinning technology. Woodhead Publishing, Cambridge, p 174

43. Hoffman JD, Miller RL (1997) Polymer 38:3151

44. Hoffman JD, Weeks JJ (1962) J Res Natl Bur Stand 66:13

45. Xiao H, Zhang Y, An S, Jia G (1996) J Appl Polym Sci 59:931

46. Zhao L, Du Q, Jiang G, Guo SJ (2007) J Polym Sci Part B: Polym Phys 45:16

47. Boudriche L, Calvet R, Hamdi B, Balard H (2011) Colloids Surf A: Physi 45:392

48. Ohta T (1983) Polym Eng Sci 23:697

49. Hoogsteen W, ten Brinke G, Pennings AJ (1988) Colloid Polym Sci 266:1003 